\title{
Characterization of the Effects of Borehole Configuration and Interference with Long Term Ground Temperature Modelling of Ground Source Heat Pumps
}

\author{
Ying Lam E. Law, Seth B. Dworkin* \\ Department of Mechanical and Industrial Engineering, Ryerson University, 350 Victoria Street \\ Toronto, Ontario M5B 2K3 Canada \\ *Corresponding author: seth.dworkin@ryerson.ca
}




\section{Abstract}

Ground source heat pumps (GSHPs) are an environmentally friendly alternative to conventional heating and cooling systems because of their high efficiency and low greenhouse gas emissions. The ground acts as a heat sink/source for the excess/required heat inside a building for cooling and heating modes, respectively. However, imbalance in heating and cooling needs can change ground temperature over the operating duration. This increase/decrease in ground temperature lowers system efficiency and causes the ground to foul-failing to accept or provide more heat. In order to ensure that GSHPs can operate to their designed conditions, thermal modelling is required to simulate the ground temperature during system operation. In addition, the borehole field layout can have a major impact on ground temperature. In this study, four buildings were studied-a hospital, fast-food restaurant, residence, and school, each with varying borehole configurations. Boreholes were modeled in a soil volume using finite-element methods and heating and cooling fluxes were applied to the borehole walls to simulate the GSHP operation. 20 years of operation were modelled for each building for $2 \times 2,4 \times 4$, and $2 \times 8$ borehole configurations. Results indicate that the borehole separation distance of $6 \mathrm{~m}$, recommended by ASHRAE, is not always sufficient to prevent borehole thermal interactions. Benefits of using a $2 \times 8$ configuration as opposed to a $4 \times 4$ configuration, which can be observed because of the larger perimeter it provides for heat to dissipate to surrounding soil were quantified. This study indicates that it is important to carefully consider ground temperature during the operation of a GSHP. Borehole separation distances, layout, and hybridization should be studied to alleviate ground fouling problems.

Keywords: Ground source heat pumps, thermal imbalance, temperature, borehole configurations 


\subsection{Introduction}

Ground source heat pumps (GSHPs) are an environmentally friendly alternative to conventional heating and cooling systems because of their high efficiency and low greenhouse gas emissions $[1,2]$. GSHPs use the ground as a stable heat transfer medium to provide both heating and cooling for a building.

During the operation of a GSHP, the ground acts as a heat source and heat sink in heating and cooling modes, respectively [3]. An important aspect for a well-designed GSHP system is to balance the heat extraction and injection from and into the ground throughout the year. Long-term heat extraction of the ground (heating season), to heat the building, would cause the ground temperature to gradually decrease - lowering the heating efficiency of the system (vice versa for the cooling season). Ideally, when the heating and cooling demands of a building are well balanced, the ground temperature fluctuates within a stable, desirable range. However, when the heating and cooling demands are poorly balanced, the ground temperature may migrate up or down over time, and as a result, system performance diminishes, and in extreme cases the ground may fail to accept/provide more heat from/to the building. This phenomenon is referred to as 'ground fouling' and many systems in the past have had to stop their operation due to the resulting low coefficient of performance (COP) [4]. To ensure that a design is feasible, it is important to model and project the changes in ground temperature over many years of operation. Furthermore, a deeper understanding of factors that can affect and mitigate ground fouling is sought.

GSHP systems are often designed to meet the full heating and cooling demands of buildings. When the building's heating and cooling loads are balanced, the system can operate for the designed duration. However, when there is a large imbalance of loads, the system could foul shortly after operation begins due to the change in ground temperature. This ground fouling can lead to system 
shut down, which causes economic loss, extended payback period, and occupant discomfort. Increase in ground temperature can lead to an inefficient GSHP because of low COPs as a result of inadequate heat transfer temperatures [5]. In addition, the increase in ground temperature can lead to ecological problems of species in the soil [6]. The study of ground temperature is important in GSHP designs.

Studies have shown that during the operation of a GSHP, if the cooling loads are not fully compensated by the heating loads (or vice versa), changes can be observed in ground temperature $[6,7,8]$. The change in ground temperature was most significant in the region within $0.5 \mathrm{~m}$ of the borehole [8]. It was also observed that the change in ground temperature occurs in the first few years of operation and asymptotes after the first ten years $[6,7,8]$.

For most buildings, balanced weather results in balanced heating and cooling demands. For example, in locations such as the Yangtze River, in China, studies have shown that the balance of hot summers and cold winters allowed the ground to be relatively balanced [5]. Slight imbalances in ground temperature are recovered during spring and autumn seasons, when heating and cooling demands are low [9]. Other specialized buildings, such as restaurants or skating rinks with high cooling needs, or processing plants with high heating needs, may have severely unbalanced loads. Studies of regions with very hot/very cold climate indicate that ground temperature would increase/decrease throughout the operation of the GSHP if necessary precautions are not taken [10, 11]. There are two main concerns for operating GSHPs in cold climate regions: soil temperature is too low to obtain high COPs and soil temperature cannot be maintained over time due to high load imbalances [11]. An objective of the present study is to analyze the quantification of these imbalances so that engineers can better understand how to design accordingly. 
According to ASHRAE, to achieve a balanced GSHP system, the heat pump heating-to-cooling ratio has to be 1.6-1.8:1; for every hour of cooling at full capacity, 1.6-1.8 hours of heating at full capacity is required [12]. There is a need to understand the severity and implications for buildings with load ratios outside this range.

Aside from the building function and location, it is important to assess the effects of borehole arrangements on the thermal imbalance problems. The ASHRAE handbook of design recommends that boreholes should be separated by a distance of $6 \mathrm{~m}$ when they are placed in a grid pattern [12]. It also indicated that this distance may be decreased when the boreholes are placed in a line or when the annual loads are well balanced [12]. However, no formalized method of determining such a spacing reduction currently exists in the literature.

Studies show that in an array of boreholes, the centre boreholes have the greatest temperature change compared to their surrounding boreholes [13]. To mitigate ground thermal imbalance, the centre boreholes can be removed to provide more space for surrounding boreholes to dissipate heat to and from - improving heat transfer [13]. This tactic may not always be possible due to space limitations. The present work seeks to quantify the ground temperature changes and to determine whether changing the arrangement of the boreholes can reduce the effect.

In [14], the effects of ground temperature during the operation of a single borehole (single line) and an array of boreholes was studied. The study was done by modelling a single borehole in an infinite field of soil, a line of boreholes, and an array of boreholes in a grid. Each of these configurations were used to supply heating for a building. Zero, partial, and full supply cooling loads of were applied to each configuration to determine which configuration has the greatest change in ground temperature. Results indicated that for a single borehole in an infinite field of soil, no heat balance is required to ensure that the GSHP continues to be operable. However, the 
line configuration requires at least partial balance of heating and cooling loads and the grid configuration requires full balance of loads. This study indicates that there is a need to evaluate the grid configuration of boreholes to mitigate the effects of thermal imbalance. Studies in borehole configurations are important because large numbers of GSHP installations are in grid configurations due to space limitations. A study in [15] indicated that there is interaction between boreholes, and separation distances between boreholes can be calculated to prevent thermal imbalance.

In [16] the authors used eQuest/DOE-2.2 to simulate ground temperature response to geoexchange. The eQuest/DOE-2.2 program used complicated g-functions to simulate temperatures at the borehole wall [16]. The development of these g-functions are based on cylindrical models developed by Eskilson [16, 17]. The g-functions used the step responses of the boreholes to determine the temperature distribution of the borehole field. It was concluded that the use of gfunctions were effective in reducing computation time for temperature distributions in a borehole field. The g-functions use the superposition of a single cylindrical model to model the behaviour of a borehole field. The effects of ground water filtration and surface convection were studied in [17] and were shown to be negligible in modelling. G-functions are commonly adopted by ground heat exchanger programs, such as EED [18]. These works simplify multiple borehole simulations into a single borehole simulation through the use of a g-function. A thesis in 2013 [19], added to Eskilson's work by comparing the g-functions generated by Earth Energy Design (EED) with those generated using numerical models and COMSOL Multiphysics. The finite line source results were well-validated with the results from EED. Upon validation of the line source model results, the author built numerical models using COMSOL Multiphysics to create models involving borehole 
fields that were closer to reality than other methods [19]. Further examining the results of the study, the results of the numerical model were well validated against the results from EED.

A model in [20] used hourly heat fluxes and g-functions in an EnergyPlus program to simulate the temperature changes [21]. The results of this model were validated against the analytical solution and the results were within $2^{\circ} \mathrm{C}$ error [20]. This study indicates that g-functions are highly accurate in determining the borehole wall temperature for multiple borehole simulation.

In a thesis

In [22], experimental results were validated against simulated results and ASHRAE design method results. The authors proposed the use of g-functions to simulate ground temperature response. The results indicated that using g-functions under-predicted required borehole length by $4 \%$ while the ASHRAE design method over-predicted the required borehole length by more than 100\% [22]. This study indicates that the methods proposed by ASHRAE design guidelines may result in systems that are overdesigned, increasing the upfront cost of the system.

In [23], the authors demonstrated the importance of including a temperature penalty in the calculation of ground loop length. In a case where heating and cooling hours are 1500 and 500, respectively, the temperature penalty is $-2.1^{\circ} \mathrm{C}$ [23]. However, in an extremely cooling dominant case, the temperature penalty is $+10.5^{\circ} \mathrm{C}$ [23]. The change in ground temperature due to the thermal imbalance causes the required ground loop length to increase by 1.26 and 1.51 times, respectively in the two cases. This study proposed the quantification of the temperature variation by applying a temperature penalty.

In both studies, [22] and [23], g-functions were used to predict the ground temperatures by superimposing the g-function onto a single borehole simulation to model multiple boreholes. 
Although using the g-function can accurately determine the temperature penalty associated with each borehole configuration, the distribution of temperatures surrounding each borehole cannot be easily determined. Although studies have been done with regards to the thermal interactions of boreholes using G-functions and analytical methods, few involved 3D finite element modelling of the distribution of temperatures in the complete borehole field. The model proposed in the present work provides the temperature distribution surrounding each borehole so that the complete heat extraction/injection effects can be visualized.

The problem this research seeks to solve is that of thermal imbalance. To address this knowledge gap, it is important to conduct studies to accurately model the ground temperature changes during the operation of a GSHP system. Doing so can lead to potential design solutions that can be used to alleviate the thermal imbalance problems. The novel contribution of this paper is that it simulates the heat transfer between the boreholes and their surrounding soil in a 3D finite element model. Present literature suggests the superimposing of a g-function to model the temperature penalty of various borehole configurations into a single borehole simulation. However, this method cannot model the temperature variation of different depths within the soil domain. Using this model, the temperature variation at any point in the soil domain can be determined and temperature distribution surrounding each borehole can be studied. The present study extend beyond temperature distributions in the ground and analyzed other aspects, such as the "on" and "off" cycles of the heat pump operation and the prediction of system life. The model present in this paper provides a useful tool for the geo-exchange industry, which can be used to simulate the temperature variations and distributions during the design phase of the system to ensure system efficiency. The intent of this paper is to make a contribution to the human knowledge worthy of dissemination. This study extends fundamental understanding in borehole design. 
In this study, hourly building heating and cooling loads were processed to calculate hourly borehole heat fluxes. A model was created using COMSOL Multiphysics [24] to simulate the borehole field geometry. Hourly conditions were applied to the geometry and the simulation was performed for a 20 year time period. The analysis was repeated for $2 \times 2,4 \times 4$, and $2 \times 8$ configurations and comparative analyses were performed.

\subsection{Methodology}

The methodology used in this paper consists of a two-part process; i) performing building energy simulation, and using the predicted heating and cooling loads to calculate hourly heat flux using MATLAB [25], and ii) simulation of ground temperature using COMSOL Multiphysics finite element heat transfer methods [24]. In the first part, building loads are determined using building energy simulation data generated from eQuest [26] and processed using MATLAB to create an accurate set of transient heat flux boundary conditions. Afterwards, a model is created using COMSOL Multiphysics to simulate operating borehole exchangers in the ground. The loads generated in the first step are used as boundary conditions for the finite element model.

Using this methodology, some assumptions were made. It was assumed that there is negligible groundwater movement in the soil volume studied. In addition, soil properties and GSHP system COP were assumed to be constant throughout the study period regardless of the change in ground temperature.

\subsection{Building Loads}

The procedure used to process the building heating and cooling demands into finite element model boundary conditions is shown schematically in Figure 1. 


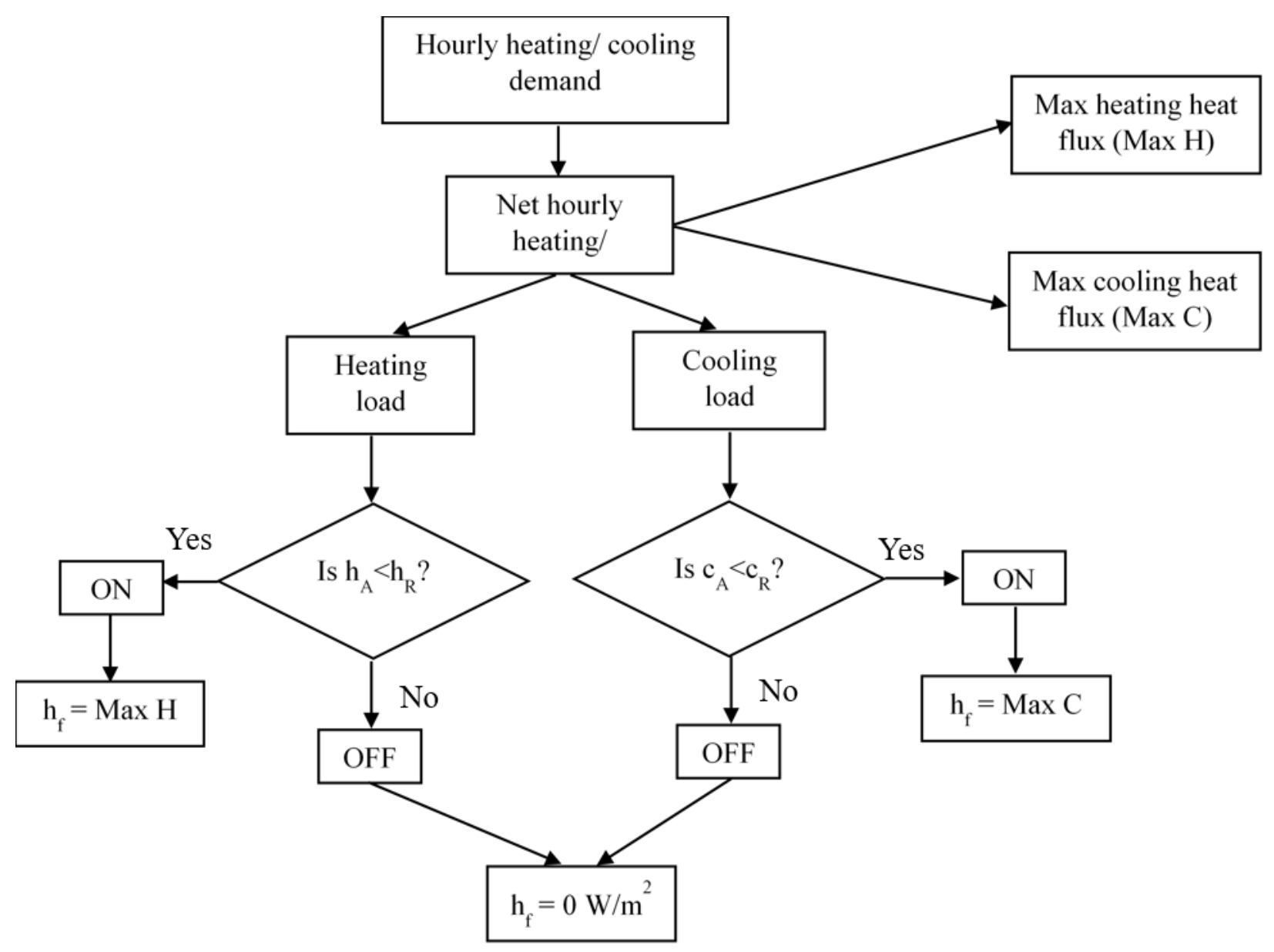

Figure 1: Hourly heat flux calculation

First, net hourly building heating and cooling loads were determined for various buildings using eQuest. Positive loads indicate cooling demands (excess heat transferred into the ground); negative loads indicate heating demands (heat extracted from the ground). Then, the maximum loads (for heating and cooling) were determined from the net demands. Using the classical methodology presented in [27], the design ground loop lengths were determined for each building. The maximum loads were divided by the total ground loop length to obtain the heat transfer rate per unit length of pipe $(\mathrm{m})\left(\mathrm{Q}_{\mathrm{H}}\right.$ and $\mathrm{Q}_{\mathrm{C}}$, for heating and cooling, respectively). The heat transfer rates per unit length of pipe were multiplied by two to denote a U-tube installation and by the length of 
the borehole to calculate the heat transfer rate of a single borehole wall. Next, the heat transfer rate was divided by the contact surface area of the borehole to obtain maximum heat flux for heating and cooling modes $\left(\mathrm{q}_{\mathrm{H}}, \mathrm{qC}_{\mathrm{C}}\right)$.

One of three conditions were applied to each hourly load: "heating on", "cooling on", or "system off". In the "heating on" mode, the GSHP is turned on for heating and the full heat flux for heating mode is applied to the boundary. In the "cooling on" mode, the GSHP is turned on for cooling and the full heat flux for cooling mode is applied to the boundary. While variable speed compressors for GSHPs exist, many systems operate in an on/off scenario, so that assumption is made in the present work. During "system off” mode, typically when demands are low or zero, the GSHP is turned off and the building's heating/cooling demands are assumed met by the residual heating/cooling from the immediately previous hour of operation. In this case, heat flux applied to the boundary is $0 \mathrm{~W} / \mathrm{m}^{2}$ and heat is free to dissipate to the surrounding soil. The operating heat fluxes of the three conditions are summarized in Table 1.

Table 1: Summary of heat flux conditions

\begin{tabular}{cccc}
\hline Condition & Heating & Cooling & Heat Flux $\left(\mathrm{W} / \mathrm{m}^{2}\right)$ \\
\hline 1 & ON & OFF & Max heating heat flux \\
2 & OFF & ON & Max cooling heat flux \\
3 & OFF & OFF & 0 \\
\hline
\end{tabular}

If the heating required $\left(h_{R}\right)$ is less than the heating available $\left(h_{A}\right)$, "heating on" mode is on for one hour. If the cooling required $\left(c_{R}\right)$ is less than the cooling available $\left(c_{A}\right)$, "cooling on" mode is on for one hour.

Since the heat pump generates waste heat during its operation, it is important to properly account for this heat as it could contribute to or alleviate thermal imbalance. In the winter, the heat 
generated by the heat pump can help restore the ground temperature and in the summer, the heat generated contributes to a greater heat removal requirements. This heat can be quantified using the heat pump's coefficient of performance (COP). In this study, a COP of 4 was used for heating and an infinite COP (free cooling) was applied for cooling mode because cooling can occur naturally from high to low temperature. Few installations exist that utilize passive cooling, however, this assumption is sufficient for the purpose of developing a model for ground temperature response.

Since the coefficient of performance of a heat pump is defined by the heat output divided by the compressor work. The net heat extracted (or injected) into the ground can be calculated by the difference (or sum) of heat output and heat released by the heat pump. This relationship was used to derive a factor that takes the COP into account for heat flux calculations (Eq. 1, Eq. 2).

$$
\begin{aligned}
& H_{f}=\frac{C^{O P} P_{h}-1}{C P_{h}} \\
& C_{f}=\frac{\operatorname{COP}_{c}+1}{\operatorname{COP}_{c}}
\end{aligned}
$$

Where $H_{f}$ is the heat flux adjustment factor for heating, and $C_{f}$ is the heat flux adjustment factor for cooling.

By multiplying heat flux conditions by $H_{f}$ in heating mode and $C_{f}$ in cooling mode, the net heat flux of a borehole can be estimated.

In this simulation, the heating COP is assumed to be 4.0 and free cooling is assumed. The heat flux calculated is based on the maximum required load for heating and cooling modes. The value of these heat fluxes are presented in detail in section 3.1. Consistent with [28], for every $1^{\circ} \mathrm{C}$ drop in entering fluid temperature, the heating COP decreases by 0.06 . Also, for every $1^{\circ} \mathrm{C}$ increase in entering fluid temperature, the cooling COP decreases by 0.1 . For simplicity, however, a constant 
COP was selected in this simulation. Although modelling a constant COP may cause errors in some of the computed values, the change is not expected to affect the qualitative trends present, and associated analysis. The increasing/decreasing trends of the overall ground temperature and the thermal interactions of borehole configurations are unaffected. The daily fluctuation of ground temperature will be affected by the hourly varying COP, however, the average daily ground temperature will remain the same.

Annual heating and cooling heat fluxes were repeated for 20 years to depict the heating and cooling operation of a GSHP system for a typical major maintenance cycle.

\section{$\underline{2.2 \text { Finite Element Simulation }}$}

A 3D symmetrical model was created using COMSOL Multiphysics to simulate a series of boreholes in working conditions during a 20 year period. Soil properties from Table 3 were applied to the soil geometry. Uniform soil property was applied to the model. Studies in [29] found that using a single soil layer for modelling resulted in little difference in overall ground temperature change compared to multiple soil layers.

In the finite element simulation, it was assumed that the soil properties remain constant throughout the simulation time. The soil domain dimensions used in the simulations are summarized in Table 2. It was also assumed that negligible ground water movement was present within the soil domain. The pipe geometry in the borehole was assumed to be a single U-tube. The borehole resistance associated with this geometry was handled in the determination of total piping length required for each building. The resulted heat flux was applied to the borehole wall of the model.

Table 2: Soil domain dimensions

Borehole configuration Soil domain dimensions




\begin{tabular}{cc}
\hline $2 \times 2$ & $40 \mathrm{~m} \times 40 \mathrm{~m} \times 150 \mathrm{~m}$ \\
$4 \times 4$ & $70 \mathrm{~m} \times 70 \mathrm{~m} \times 150 \mathrm{~m}$ \\
$2 \times 8$ & $70 \mathrm{~m} \times 100 \mathrm{~m} \times 150 \mathrm{~m}$ \\
\hline
\end{tabular}

Table 3: Soil properties

\begin{tabular}{ccc}
\hline Property & Value & Unit \\
\hline Thermal conductivity & 1.63 & $\mathrm{~W} /(\mathrm{m} . \mathrm{K})$ \\
Density & 2050 & $\mathrm{~kg} / \mathrm{m}^{3}$ \\
Heat capacity & 1840 & $\mathrm{~J} /(\mathrm{kg} . \mathrm{K})$ \\
\hline
\end{tabular}

In the multiple borehole model, a quarter of the boreholes were modelled in a rectangular prism of soil and mirror boundary conditions were used on two sides to effectively quadruple the domain. In the $2 \times 2$ model, a single borehole geometry was created and in the $4 \times 4$ model, four $100 \mathrm{~m}$ boreholes were created. Boreholes typically range between $20 \mathrm{~m}$ and $200 \mathrm{~m}$ in depth, with most modern installations targeted at $150 \mathrm{~m}$ or more [30,31]. Symmetry boundary conditions were applied to the inner faces of the prism to model 4 times the number of boreholes modelled in the geometry as presented in Figure 2a. Hourly heat fluxes were applied to the borehole walls as presented in Figure 2b, using an exact time stepping technique in which hourly heat fluxes are exactly read from the tabulated values rather than interpolated. This method ensures that no random time-stepping is done and consistent results can be obtained in all trials. The simulation uses a parallel direct sparse solver (PARDISO) which uses LU decompositions in its solutions. The solver uses the backward differentiation formula (BDF) to calculate soil temperature at each time step [24]. An open boundary condition was applied to the exterior and bottom faces of the prism to approximate infinite domain size at initial temperature and zero heat flux beyond the boundary as presented in Figure 2c. It was assumed that the top face of the geometry is fully insulated. Ambient air temperature was neglected since ambiant conditions at most only affect the 
first $15 \mathrm{~m}$ of soil [32]. As such, if thermal imbalance were to occur, the region of soil directly adjacent to GSHPs with vertical ground loops are not affected by seasonal ambient temperature fluctuations on the surface. Any depth beneath the first $15 \mathrm{~m}$ of soil is solely considered to be influenced by the GSHP system and soil properties.
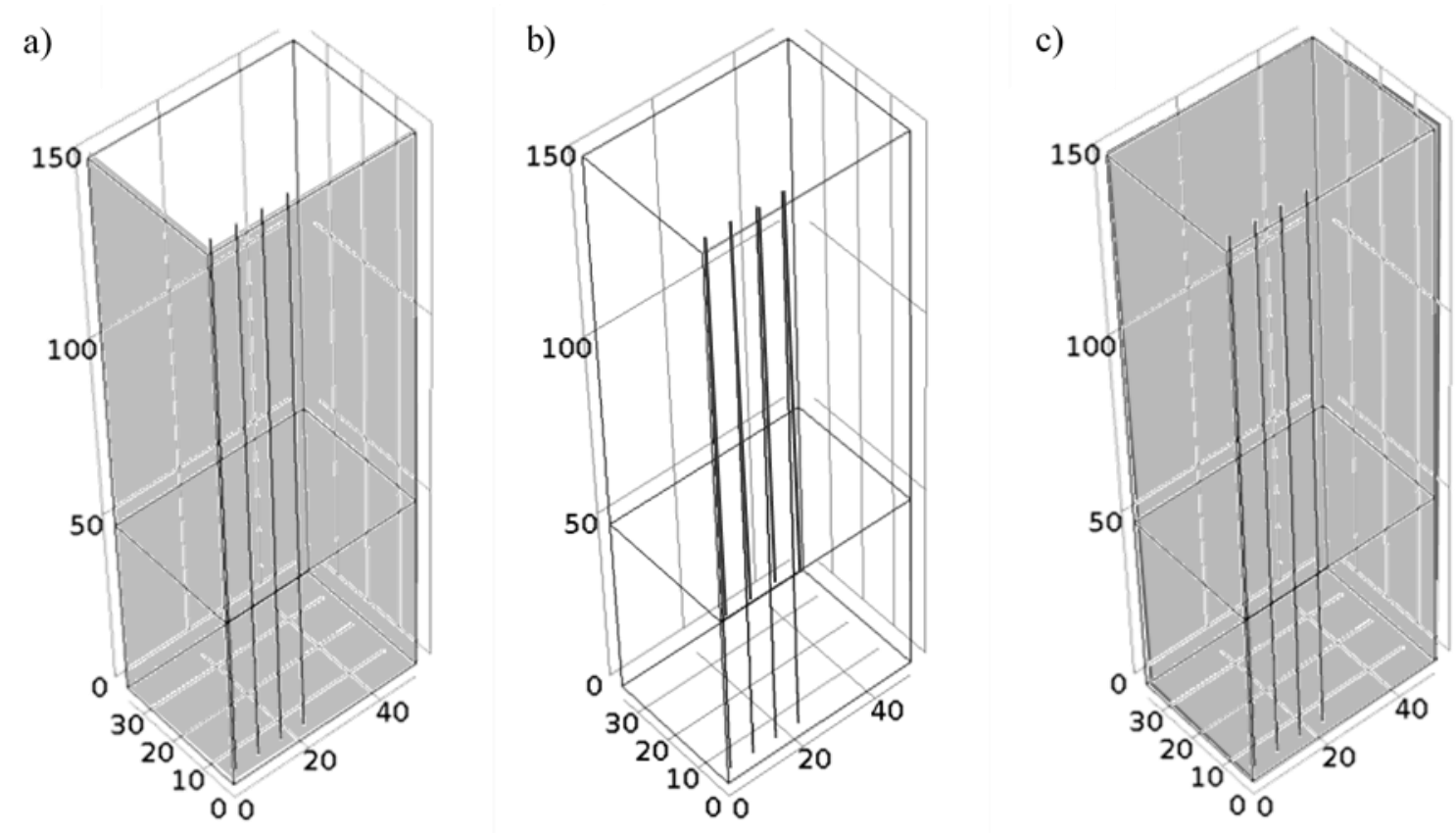

Figure 2: Boundary conditions for (a) symmetry boundary, (b) heat flux boundary, and (c) open boundary

\subsection{Model validation}

Using the same validation procedure as in Kuzmic et al., [33] the finite element model was validated against analytical and experimental results. Finite element models were created using the same parameters and boundary conditions as in [33].

\subsubsection{Validation against analytical results}

The finite element model was validated against the analytical results presented in [33]. The model analytical results were generated using a finite line-source model. The model parameters are 
outlined in Table 4. The geometry was created using finite element methods with the computational domain shown in Figure 3a. A $150 \mathrm{~m}$ borehole with radius of $0.01 \mathrm{~m}$ was modelled within a $4.34 \mathrm{~m}$ radius soil volume. A boundary temperature of $0^{\circ} \mathrm{C}$ was applied to the top and bottom boundaries of the soil volume. Zero gradient conditions were applied to the inner and outer soil boundaries. A heat flux of $1592 \mathrm{~W} / \mathrm{m}^{2}$ was applied to the borehole wall. A summary of the conditions applied are presented in Figure 3b.

Table 4: Parameters for analytical validation (reproduced from [33])

\begin{tabular}{cc}
\hline Parameter & Value \\
\hline Borehole height $(\mathrm{H})$ & $150 \mathrm{~m}$ \\
Radial soil domain $\left(\mathrm{r}_{\infty}\right)$ & $4.34 \mathrm{~m}$ \\
Underneath soil domain $\left(\mathrm{L}_{\mathrm{b}}\right)$ & $11.25 \mathrm{~m}$ \\
Soil conductivity $\left(\mathrm{k}_{\text {soil }}\right)$ & $2.4 \mathrm{~W} \mathrm{~m}^{-1} \mathrm{~K}^{-1}$ \\
Soil density·soil specific heat & $3.9 \times 10^{6} \mathrm{~J} \mathrm{~m}^{-3} \mathrm{~kg}^{-1}$ \\
Heat transfer rate $\left(\mathrm{q}_{1}\right)$ & $100 \mathrm{~W} \mathrm{~m}^{-1}$ \\
\hline
\end{tabular}


(a)

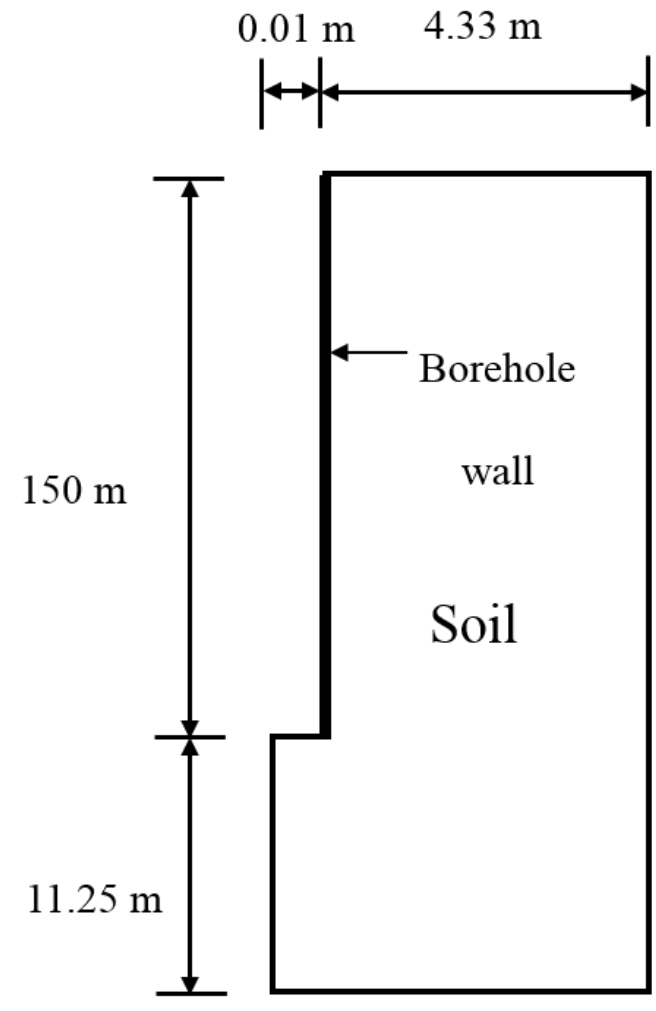

(b)

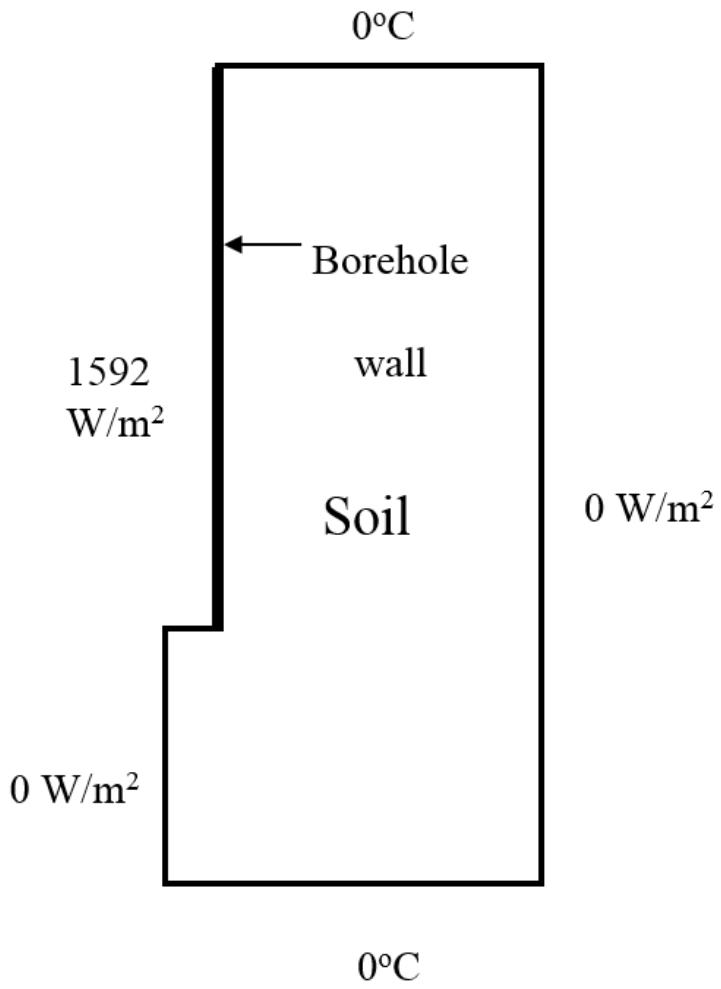

Figure 3: Analytical validation model (a) geometry and (b) boundary conditions A 100 hour simulation was conducted and the results of the finite element simulation for temperature as a function of radius at $75 \mathrm{~m}$ are illustrated in Figure 4 It can be observed in the figure that the finite element model produced results that were in line with those obtained from the analytical model. The finite element results are within $0.08^{\circ} \mathrm{C}$ error of the analytical results. 


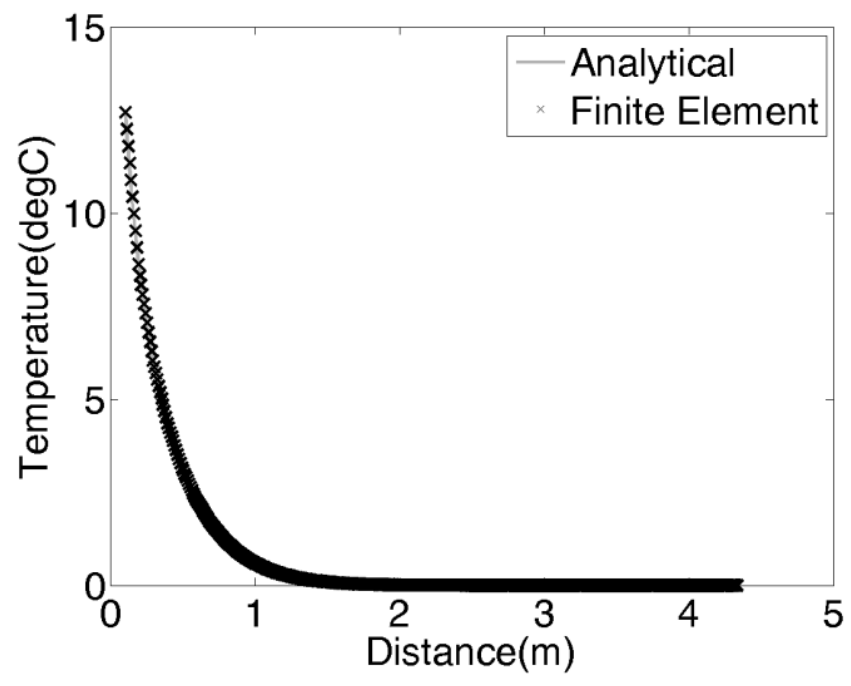

Figure 4: Analytical validation results

\subsubsection{Validation against experimental results}

The finite element results were validated against experimental results presented by [34]. In the experiment in [34], an aluminum pipe was set up inside a wooden box filled with sand to imitate the operation of a borehole ground heat exchanger. Borehole and soil temperatures were recorded and published in [34]. In this section, a finite element model was created according to the parameters provided in [34] and the analysis was performed. The results of the simulation are compared to the experimental results.

A layout of the boundary conditions and geometry are outlined in Table 5 and Figure 5, respectively. The geometry of the finite element model built to generate results for the experimental validation is illustrated in Figure 5a. The geometry depicts an $18.3 \mathrm{~m}$ deep borehole inside a $37.5 \mathrm{~m}$ radius of soil. The boundary conditions used in the model are summarized in Figure 5b. Soil and grout properties from Table 5 were applied to the geometry. An average of pipe inlet and outlet temperatures from [34] were applied as a temperature boundary to the interface between the pipe and the grout. A temperature boundary was used rather than a heat flux boundary, so as 
to be consistent with the conditions of the experimental data. A zero gradient was applied to all other boundaries. The thermal storage of the circulating water and grout are taken into account because the initial temperature of the borehole is set to $22^{\circ} \mathrm{C}$. Although the thermal storage of the circulating water are not modeled, the thermal storage of the grout is considered. The model handles the grout as a resistive layer around the circulating fluid.

Table 5: Parameters for experimental validation

\begin{tabular}{cc}
\hline Parameter & Value \\
\hline Grout conductivity & $0.73 \mathrm{~W} \mathrm{~m}^{-1} \mathrm{~K}^{-1}$ \\
Grout density·grout specific heat & $3.9 \times 10^{6} \mathrm{~J} \mathrm{~m}^{-3} \mathrm{~kg}^{-1}$ \\
Soil conductivity & $2.82 \mathrm{~W} \mathrm{~m}^{-1} \mathrm{~K}^{-1}$ \\
Soil density·soil specific heat & $2.9 \times 10^{6} \mathrm{~J} \mathrm{~m}^{-3} \mathrm{~kg}^{-1}$ \\
Soil radius & $37.5 \mathrm{~m}$ \\
Grout radius & $0.063 \mathrm{~m}$ \\
Pipe radius & $0.01 \mathrm{~m}$ \\
Borehole depth & $18.3 \mathrm{~m}$ \\
Soil beneath borehole & $5.5 \mathrm{~m}$ \\
\hline
\end{tabular}


(a)

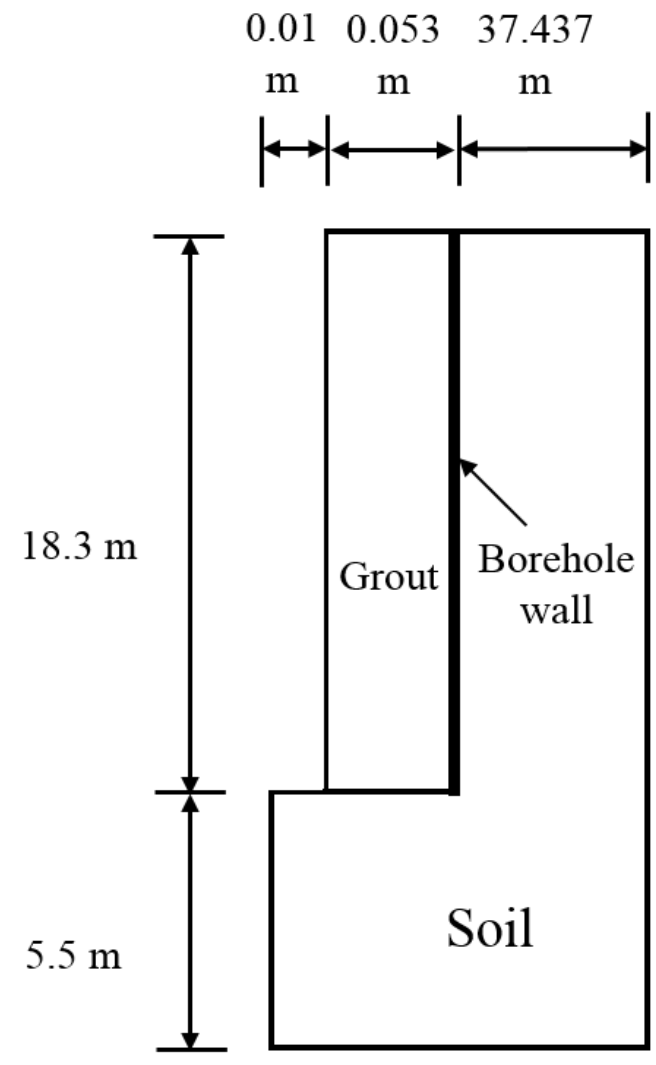

(b)

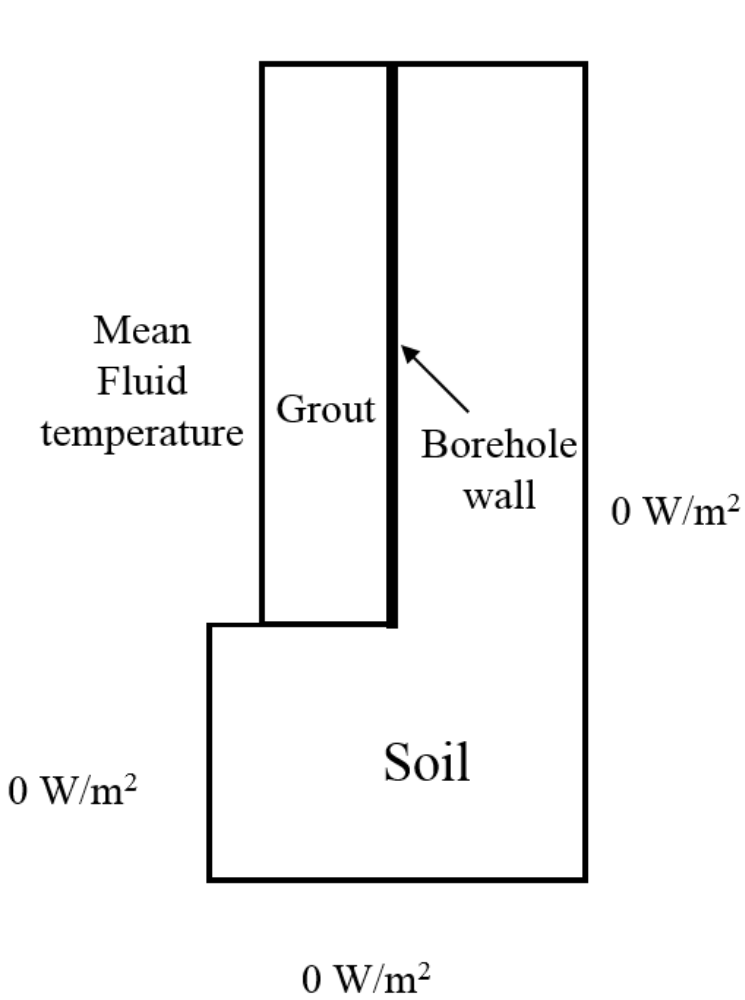

Figure 5: Experimental validation model (a) geometry and (b) boundary conditions The simulation was conducted for a one-thousand minute study period at time steps of one minute. The results of the finite element simulation are summarized in Figure 6. Figure 6 compares results from the finite element simulation with results from the experimental data for three data points: 24 $\mathrm{m}, 44 \mathrm{~m}$, and $65 \mathrm{~m}$, away from the centre of the borehole. The finite element simulation results are within $1.5 \%$ of the experimental data. The greatest difference can be found at points that are closest to the centre of the borehole. As the distance away from the borehole increases, the temperature difference between the experimental data and model predictions decreases. It can be concluded that the finite element model is well validated by the experimental data. 


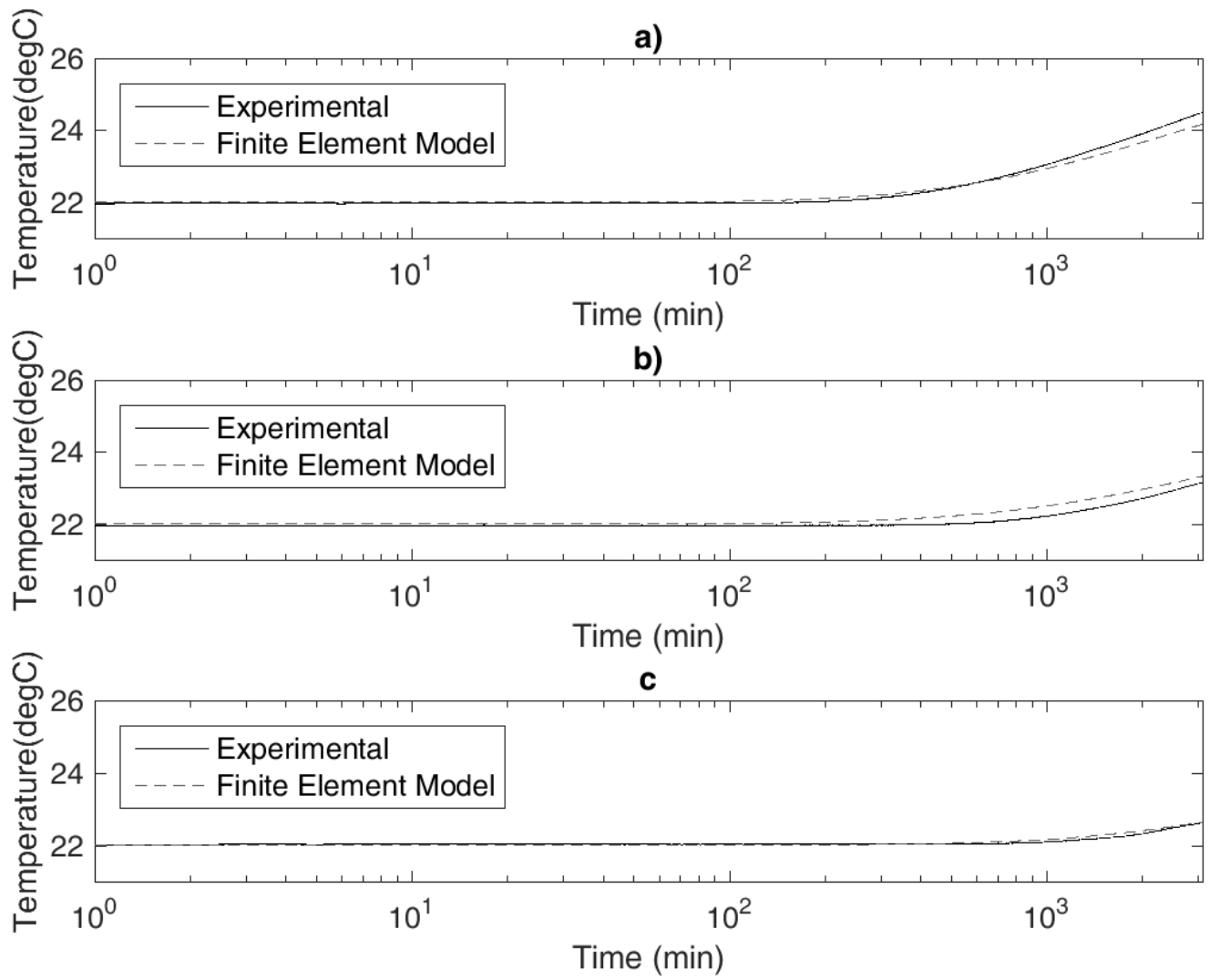

Figure 6: Experimental validation results for a point (a) $24 \mathrm{~m}$, (b) $44 \mathrm{~m}$, and (c) $65 \mathrm{~m}$ away from the centre of the pipe

\subsection{Results}

\subsection{Hourly heat flux}

Four buildings were considered in this study: a hospital, fast-food restaurant, residence, and school. Each of the four buildings are real, and either had a GSHP installed or considered [35,36]. The annual building loads of the four buildings are illustrated in Figure 7. In Figure 7, the cooling and heating requirements of the buildings can be clearly seen. The cooling requirements are illustrated in light gray and the heating requirements are illustrated as negative cooling load in dark gray. It can be observed from the figures that the hospital is slightly heating dominated (Figure 2a), the 
fast-food restaurant is extremely cooling dominated (Figure 2b), the residence is heating dominated (Figure 2c), and the school is slightly cooling dominated (Figure 2d). The heating and cooling balance is relatively even in the hospital and in the school. Of the 8760 hours in a year, only a few hours require heating in the fast-food restaurant because of the large amount of excess heat emitted from the kitchen.

a)

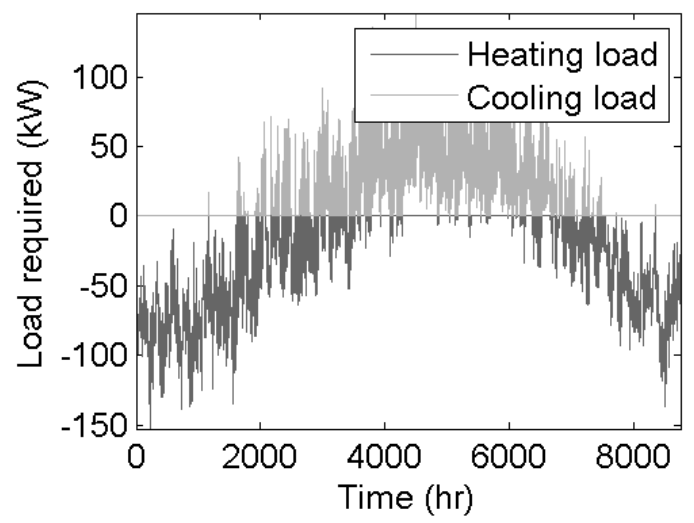

c)

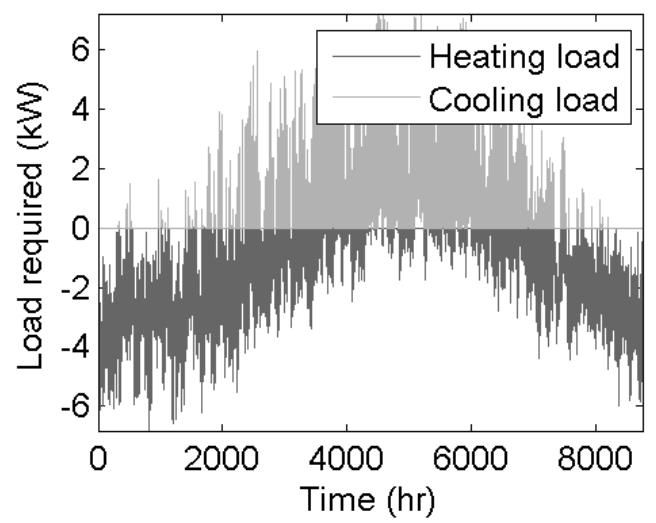

b)

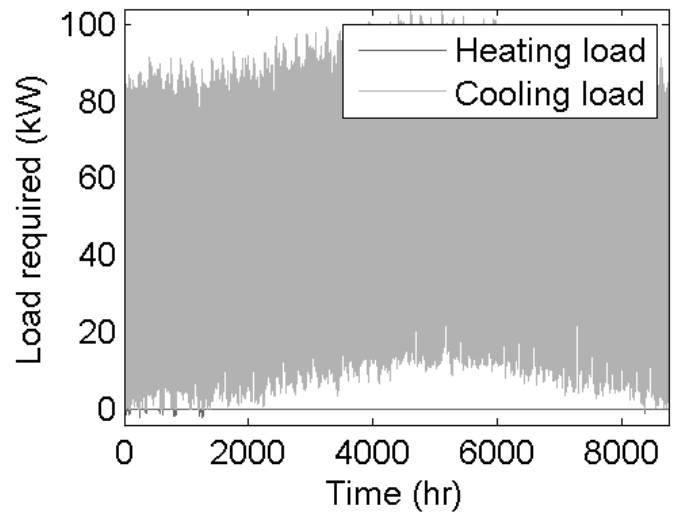

d)

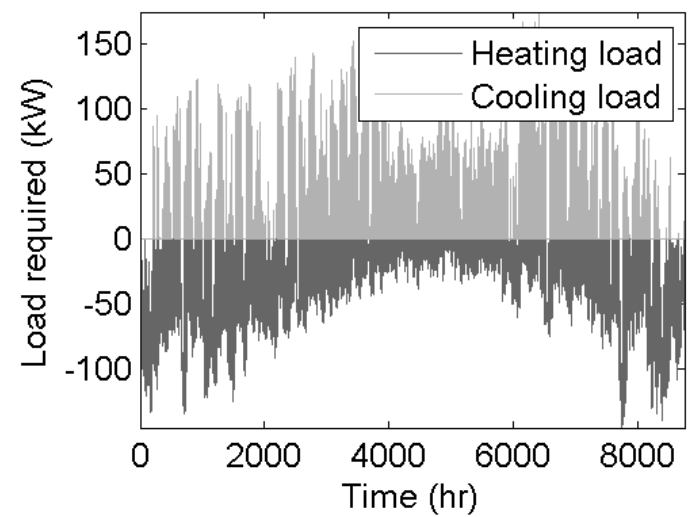

Figure 7: Building loads for (a) hospital, (b) fast-food restaurant, (c) residence, and (d) school The hourly building loads were read into the algorithm described in the previous section and the hourly boundary heat fluxes were calculated for each $100 \mathrm{~m}$ borehole. One year's hourly heat fluxes were calculated and are presented in Figure 8. Since the fast-food restaurant requires cooling throughout the year, only hours 2200 to 2400 were presented in the Figure $8 \mathrm{~b}$ to show the on and 
off cycles of the heat pump. When the heat pump is on, the heat flux of $161.44 \mathrm{~W} / \mathrm{m}^{2}$ is applied to the borehole boundary. When the heat pump is off, a zero heat flux is applied to the boundary. The positive heat fluxes in dark gray denote heat that is moved into the ground and negative heat fluxes in light gray denote heat that is extracted from the ground. A summary of the total heating and cooling hours and heat fluxes is shown in Table 6. Large thermal imbalances can be observed in the fast-food restaurant and a slight imbalance of heating and cooling hours can be observed in the three remaining buildings.

a)

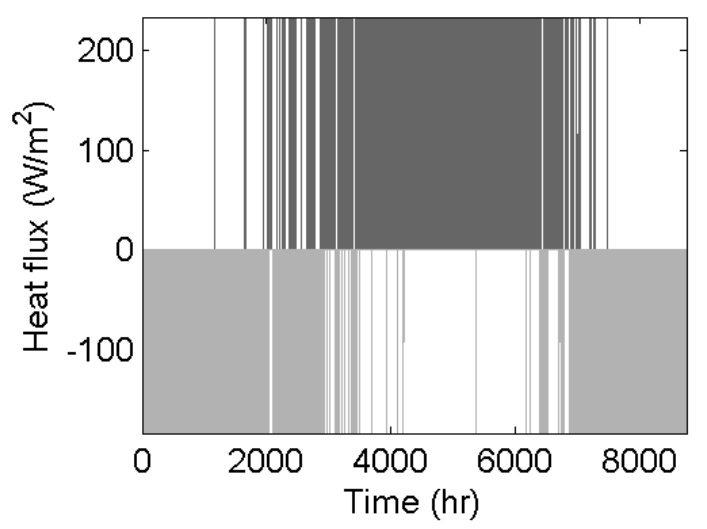

c)

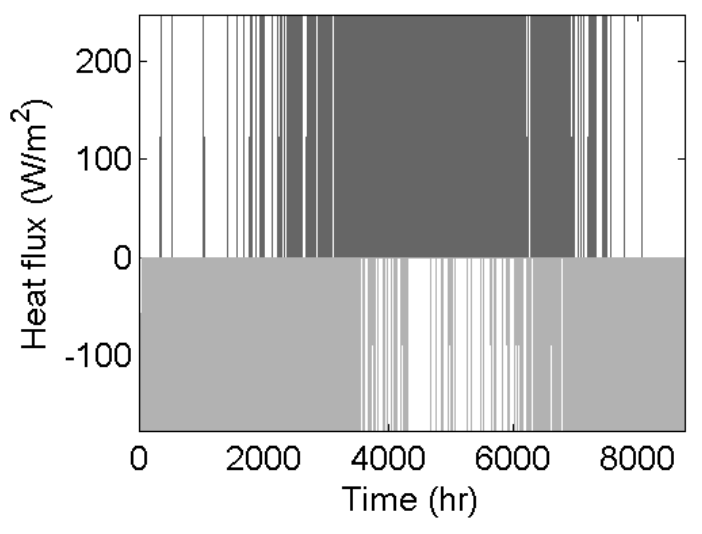

b)

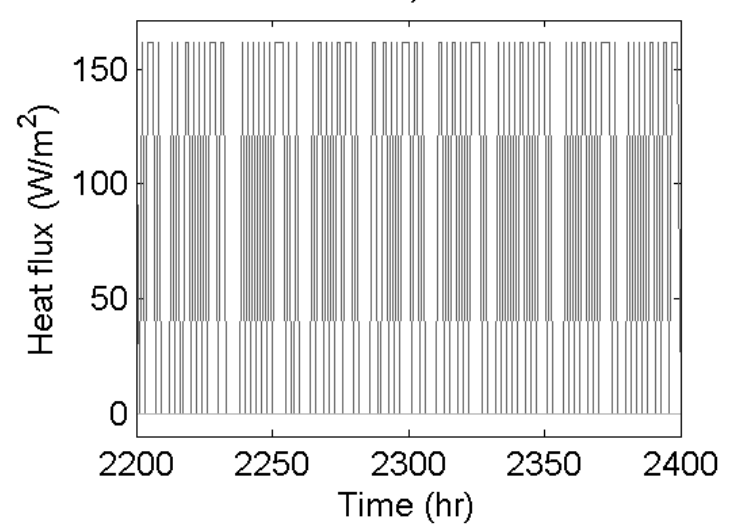

d)

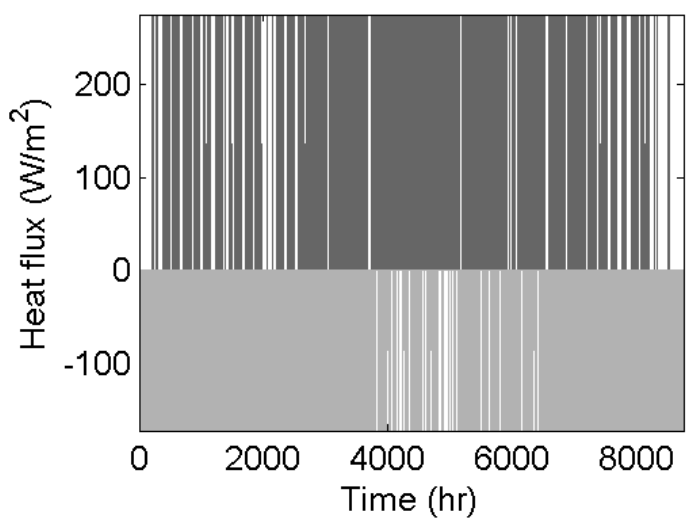

Figure 8: Hourly borehole boundary heat flux for (a) hospital, (b) fast-food restaurant, (c) residence, and (d) school buildings $\left(\mathrm{W} / \mathrm{m}^{2}\right)$ 
Table 6: Summary of heating/cooling heat fluxes and system on/off times for a hospital, fastfood restaurant, residence, and school

\begin{tabular}{ccccccc}
\hline Building & $\begin{array}{c}\text { Heating heat } \\
\text { flux }\left(\mathrm{W} / \mathrm{m}^{2}\right)\end{array}$ & $\begin{array}{c}\text { Cooling heat } \\
\text { flux }\left(\mathrm{W} / \mathrm{m}^{2}\right)\end{array}$ & $\begin{array}{c}\text { Cooling } \\
(\mathrm{hrs})\end{array}$ & $\begin{array}{c}\text { Heating } \\
(\mathrm{hrs})\end{array}$ & $\begin{array}{c}\text { System } \\
\text { off }(\mathrm{hrs})\end{array}$ & $\begin{array}{c}\text { Heating hr } \\
\text { to cooling } \\
\text { hr ratio }\end{array}$ \\
\hline Hospital & 233.55 & -183.60 & 1201 & 1588 & 5971 & 1.322 \\
$\begin{array}{c}\text { Fast-food } \\
\text { restaurant }\end{array}$ & 161.44 & -4.82 & 4571 & 10 & 4179 & 0.002 \\
Residence & 247.87 & -176.83 & 1066 & 1858 & 5836 & 1.743 \\
School & 275.19 & -172.64 & 1169 & 1699 & 5892 & 1.453 \\
\hline
\end{tabular}

\section{$\underline{3.22 \times 2 \text { configuration }}$}

By modelling one borehole with symmetry conditions, a $2 \times 2$ borehole configuration was created. Heat flux boundary conditions depicted in Figure 8 were applied. After a 20 year simulation, the ground temperature at 3 points were studied. The location of the three points can be found in Figure 9. Point $\mathrm{A}$ is located in the centre of the 4 boreholes. Point $\mathrm{C}$ is located $5 \mathrm{~m}$ away from the corner borehole at a 45 degree angle. Point B is located at the same $x$-axis location as point $\mathrm{C}$ and located at $y=0$ on the $y$-axis. The three points are chosen to study the effects of far field temperature (point C), four borehole interaction (point A), and two borehole interaction (point B). Boundary conditions were applied to the geometry and the simulation was performed for the four buildings. 


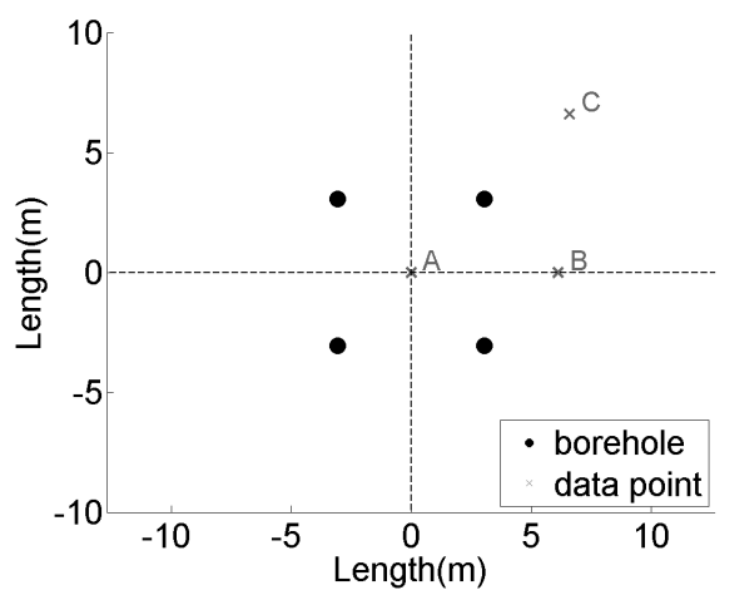

Figure 9: 2x2 borehole layout

The results of the simulations are summarized in Figure 10. Annual fluctuations can be seen for each case due to seasonal changes. The highest ground temperatures occur in the peak summer months when large amounts of excess heat was released into the ground to provide cooling for the building. The lowest ground temperatures occur in the peak winter months when large amounts of heat was extracted out of the ground to provide heating for the building. 

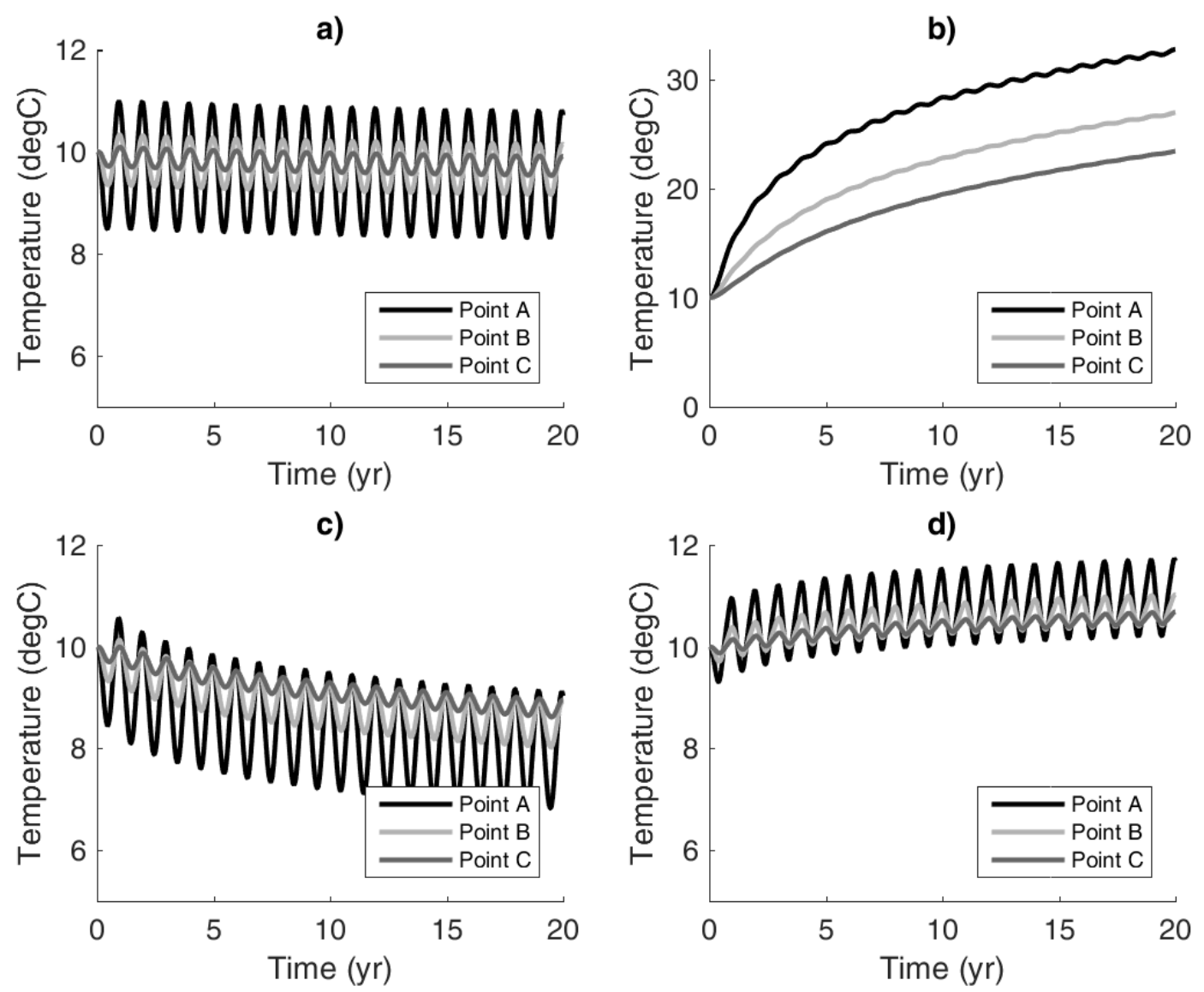

Figure 10: Ground temperature at points A, B, and C for (a) hospital, (b) fast-food restaurant, (c) residence, and (d) school buildings for $2 \times 2$ borehole configuration. A different scale is used for

(b) to depict the full predicted temperature range

The (im)balance in heating and cooling load can be clearly perceived in Figure 10. For the fastfood restaurant, the large imbalance in loads causes a large increase in ground temperature. Heat accumulation can be observed in the centre of the four boreholes (point A). After a 20 year operation period, the temperature at point $\mathrm{A}$ hikes to a maximum of $32^{\circ} \mathrm{C}$ from the initial temperature of $10^{\circ} \mathrm{C}$. This large change in ground temperature indicates that the efficiency of the system will gradually decrease within the 20 years. The actual system would become inoperable before the 20 year mark as efficiency would decline beyond tolerable values, or functionality would cease. For the fast food restaurant, it is clear that an alternative HVAC technology should be employed, or an alternative method of dissipating heat from the ground would be needed. 
From the four cases, it can be observed that the ground temperature at point $\mathrm{C}$ experiences the least change compared to points $\mathrm{A}$ and $\mathrm{B}$. The greatest heat reduction/accumulation can be observed in point A for the four cases. However, the hospital case experiences the least change in ground temperature compared to the other cases. This observation confirms that the borehole separation distance of $6 \mathrm{~m}$ may be sufficient in some cases in a $2 \times 2$ installation to prevent borehole interactions as the loads are relatively balanced.

In Figure 11, the annual average ground temperature for the four buildings are plotted. This figure illustrates the overall trend in ground temperature changes in each building over 20 years. The average is calculated by the mean of the 8760 hours of each year from the first hour on January $1^{\text {st }}$ to the last hour of December $31^{\text {st }}$. Changes in ground temperature are fast in the beginning and gradually slow down as time passes. A jump in the data can be seen in the first year because only a partial winter was experienced in the data set. As with Figure 10, the smallest change in ground temperature is found at point $\mathrm{C}$ and the largest change occurs at point A. From Figure 11, the effects of borehole interactions can also be observed. Point B's temperature is predominantly affected by the temperature of the two boreholes on the left whereas point A's temperature is affected by the temperature of all four boreholes. It is interesting to note that the curve formed by point $B$ is almost at the halfway point between point $A$ and point $C$. This observation indicates that although the boreholes are not immediately adjacent to the points, the point still experiences effects from it. Although point $\mathrm{C}$ is only adjacent to one borehole, its overall change in ground temperature is $50 \%$ of the change in point A (which is surrounded by four boreholes), because of the interactions with the other nearby boreholes.

A key difference between this model and those in literature is that the present model presents the temperature variation at different points on the soil domain. The effects of having 4, 2 and 1 
surrounding boreholes are studied for points A, B, and C. In previous studies, temperature penalties are determined using a g-function and applied to a single borehole model to depict the effects of borehole geometries [21, 22]. However, in these models, only the temperature at the borehole wall can be determined.
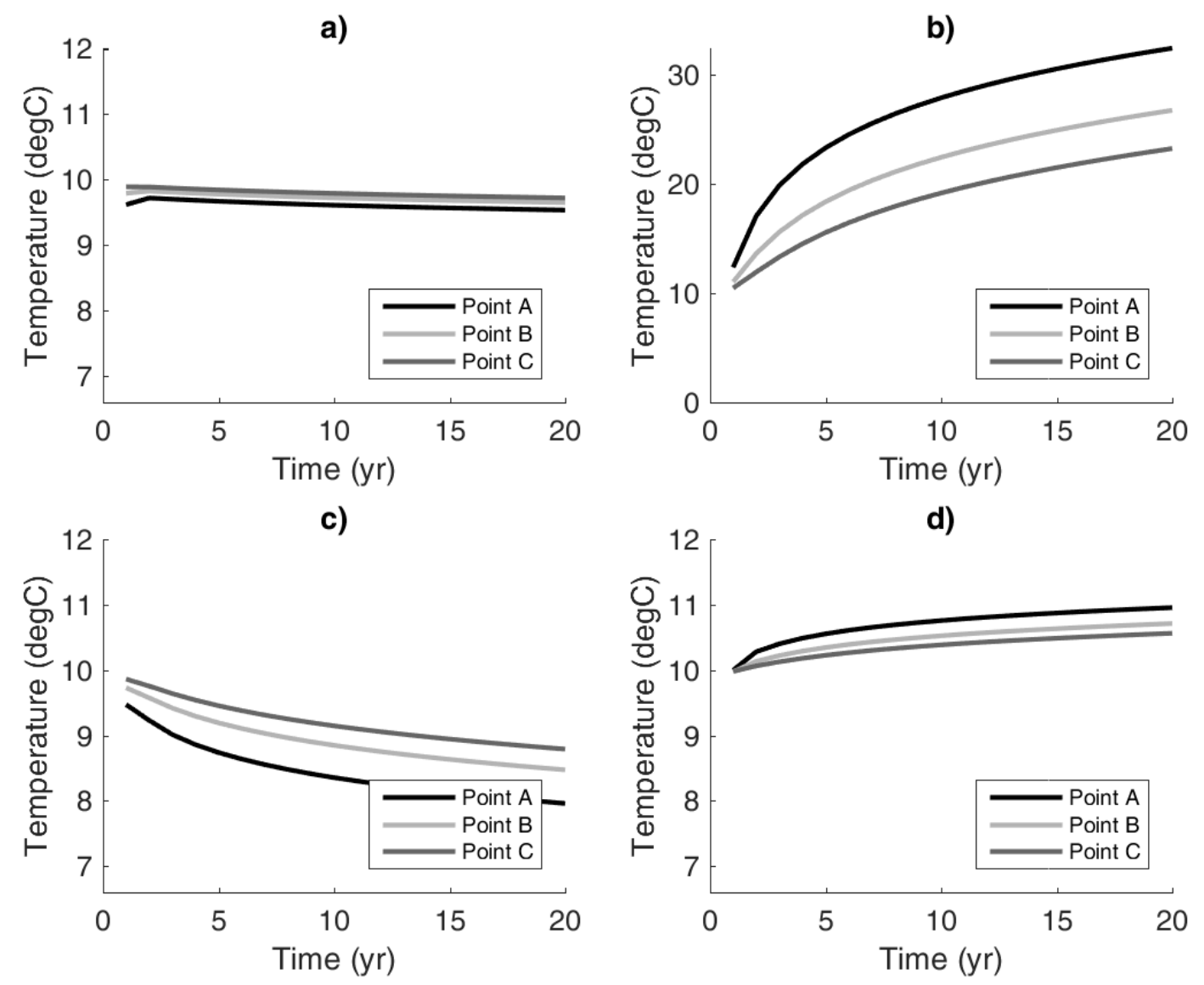

Figure 11: Average ground temperature at points A, B, and C for (a) hospital, (b) fast-food restaurant, (c) residence, and (d) school buildings for $2 \times 2$ borehole configuration

Figure 12 summarizes the ground temperature of the four buildings at point A. Large increases in ground temperature can be observed in the fast-food restaurant. Of the four buildings, the hospital ground temperature remains relatively steady over the 20 years. The residence is slightly heating dominant and the school is slightly cooling dominant, and the ground temperature can be seen to be changing by less than about $2^{\circ} \mathrm{C}$ for these cases, indicating GSHP suitability. 


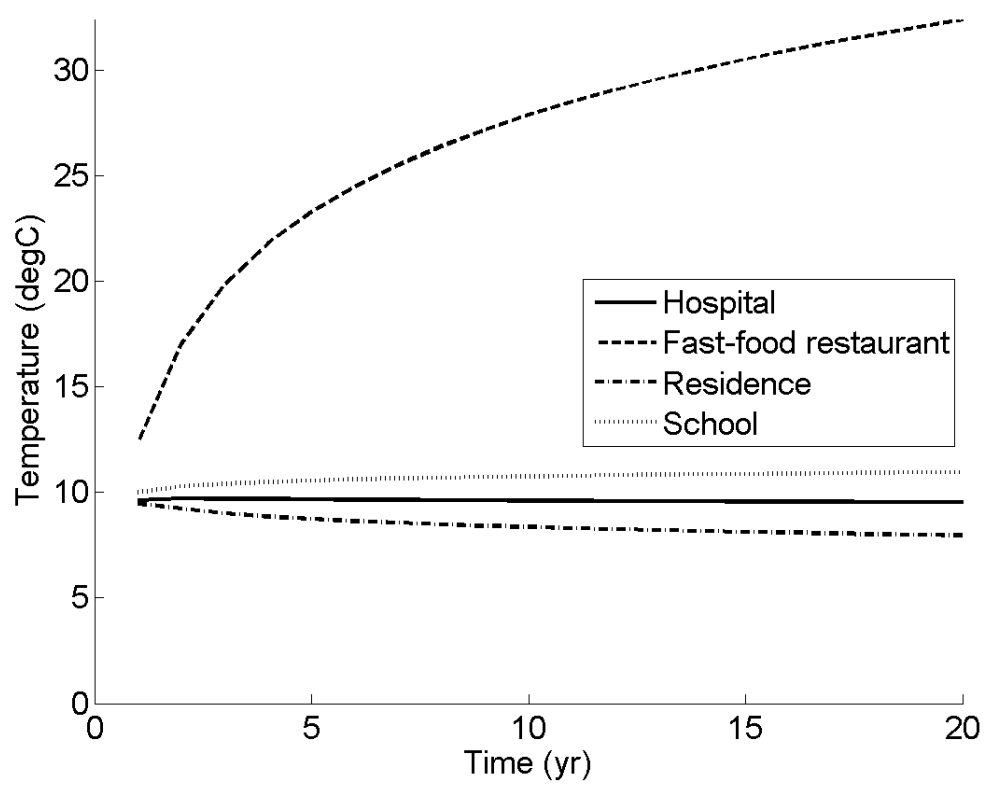

Figure 12: Point A temperature for a hospital, fast-food restaurant, residence, and school building for $2 \times 2$ borehole configuration

In Figure 13, the maximum and minimum ground temperatures for 20 years were studied for the four buildings. The maximum and minimum curves show the opposite character. As expected, the maximum ground temperature occurs in peak summer when a large amount of excess heat is transferred into the ground to achieve cooling for a building. This temperature occurs at the soil volume adjacent to the borehole walls. During this time, the minimum temperature is the far field temperature. Similarly, during peak winter when large amounts of heat are extracted from the ground, ground temperature is at its minimum. At this time, the maximum ground temperature is the far field temperature. This phenomenon can be observed in Figure 13a, c, and d where the maximum and minimum ground temperatures remain steady between $30^{\circ} \mathrm{C}$ and $-10^{\circ} \mathrm{C}$. However, in Figure 13b, the heating and cooling load imbalance is large; ground temperatures around the boreholes are greater than far field temperature even in peak winter. 
a)

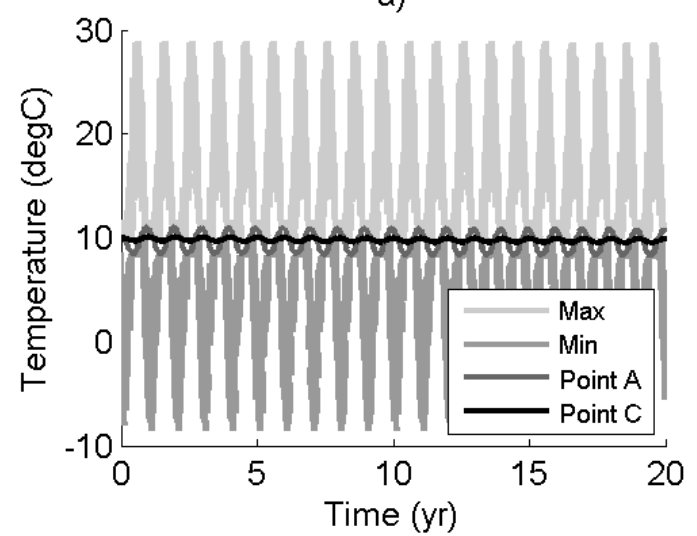

c)

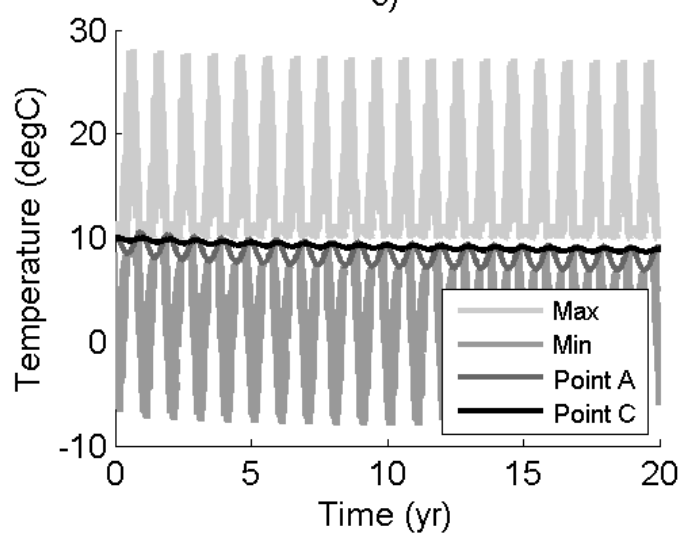

b)

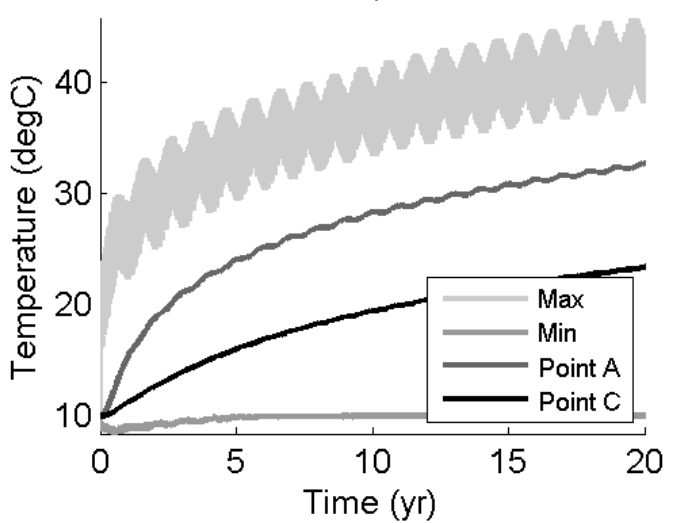

d)

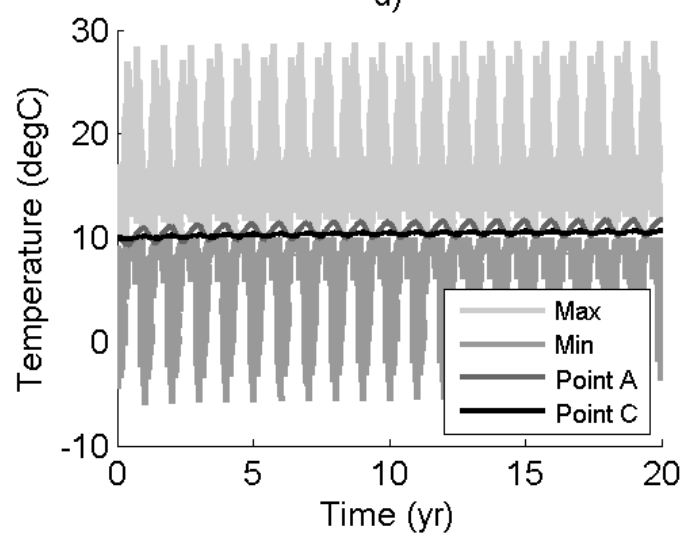

Figure 13: Maximum, minimum, point $\mathrm{A}$, and point $\mathrm{C}$ ground temperature for (a) hospital, (b) fast-food restaurant, (c) residence, and (d) school buildings for $2 \times 2$ borehole configuration

\section{$\underline{3.34 \times 4 \text { configuration }}$}

A $4 \times 4$ borehole configuration was generated by modelling four boreholes with two symmetrical soil surfaces. Points A, B, C, D, E, F, and G were studied because they were representative of the geometry as illustrated in Figure 14. Boundary conditions were applied as they were in the $2 \times 2$ borehole configuration. A 20 year simulation was performed for the geometry and the results for points A, B, and G were plotted in Figure 15. Points D, E, F and G were not plotted in the figure because they showed similar behaviour to other points. In particular, points D, F, and G show similar behaviour to point $\mathrm{B}$, and point $\mathrm{E}$ shows similar behaviour as point $\mathrm{C}$. 


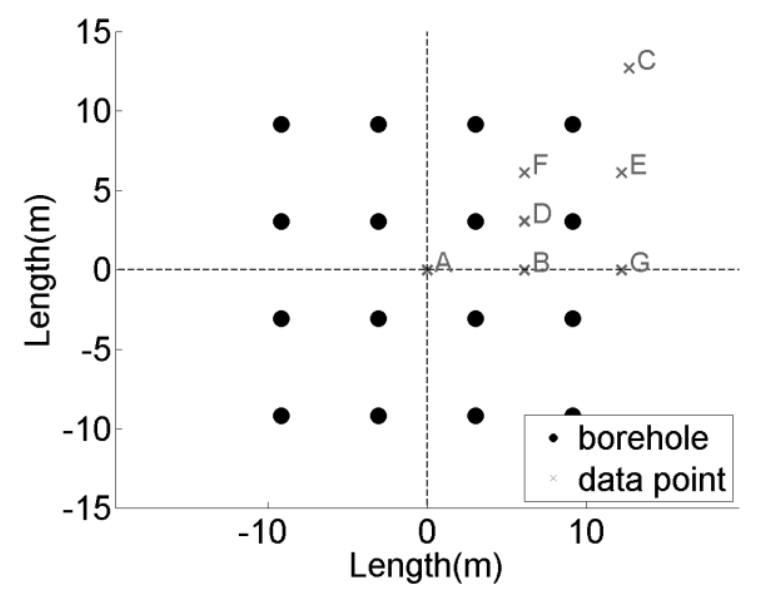

Figure 14: 4x4 borehole layout

In Figure 15, the reduction/accumulation of heat can be observed from the four buildings. Since the fluid temperature is approximately $35^{\circ} \mathrm{C}$ during cooling mode, any ground temperature above $35^{\circ} \mathrm{C}$ will not allow heat transfer from the borehole to the soil thus fouling the system. It can be observed in Figure $15 \mathrm{~b}$ that the system will begin to foul within the first five years after the beginning of operation as point $\mathrm{A}$ approaches $35^{\circ} \mathrm{C}$. The system life of less than five years indicates that the system is not appropriately designed. A potential solution to avoid system fouling is to space boreholes further apart or to hybridize the system with a device such as a cooling tower. 
a)

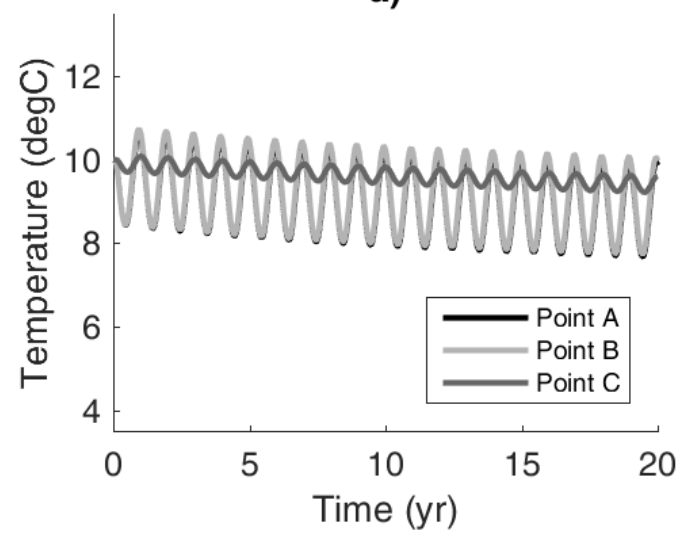

c)

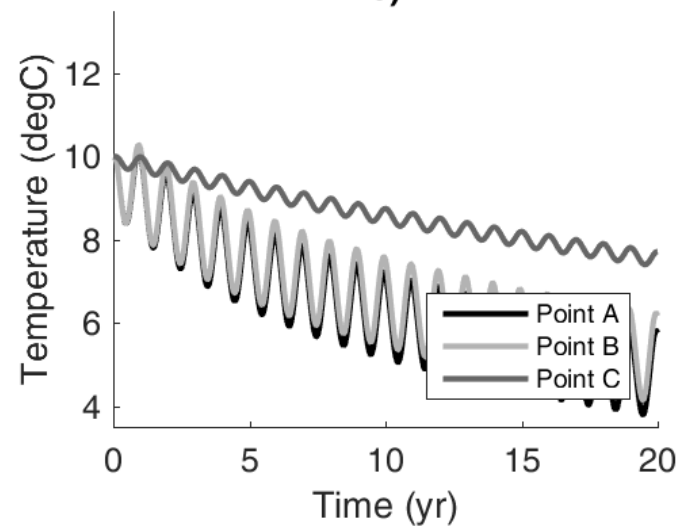

b)

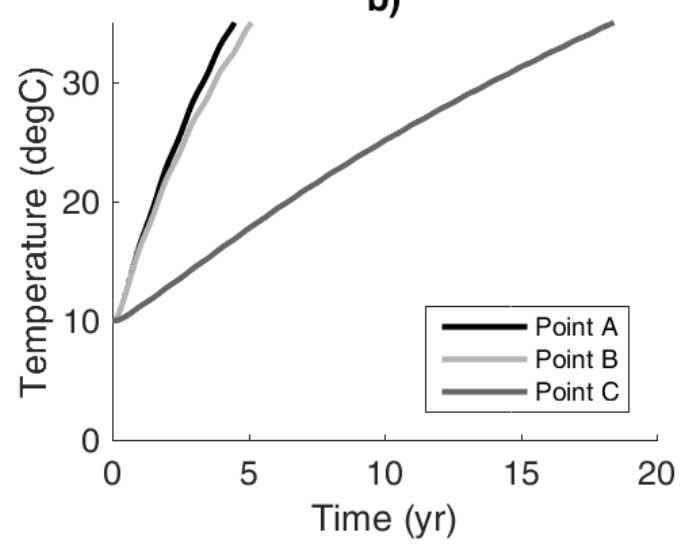

d)

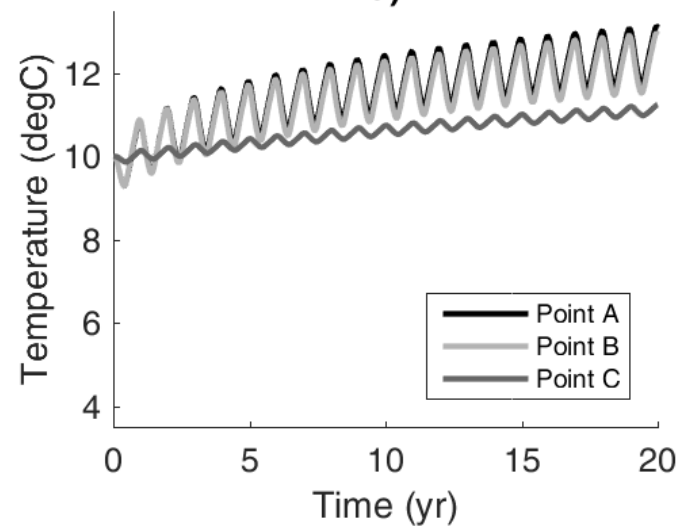

Figure 15: Ground temperature at points A, B, and C for (a) hospital, (b) fast-food restaurant, (c) residence, and (d) school buildings for $4 \times 4$ borehole configuration

Figure 16 illustrates the annual averages of ground temperatures over 20 years for points A, B, and C. It can be observed from this figure that temperatures at point A and point B are very similar. Ground temperature at point $\mathrm{C}$ increases/decreases gradually due to the effects of the surrounding boreholes. However, the change in ground temperature at that point is small. 
a)

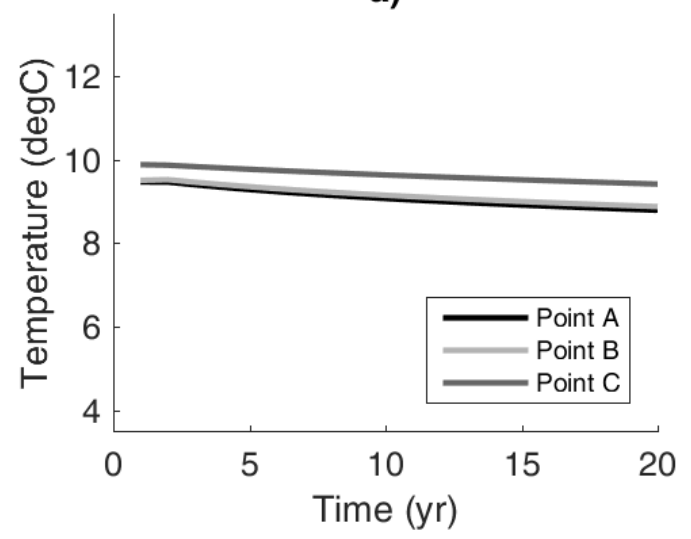

c)

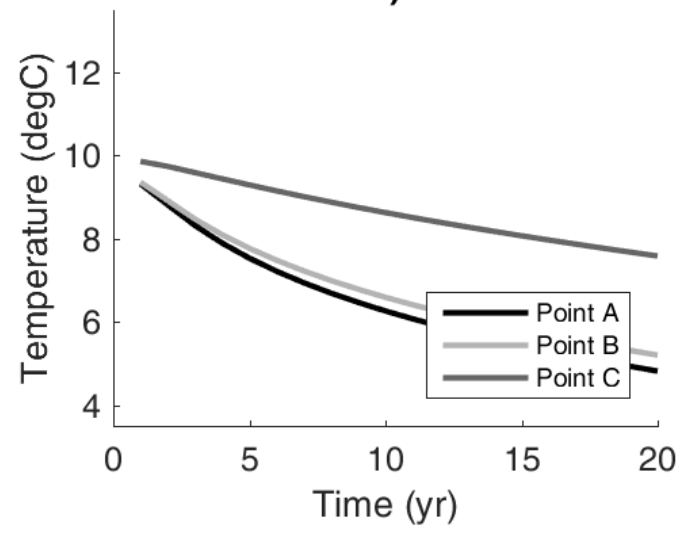

b)

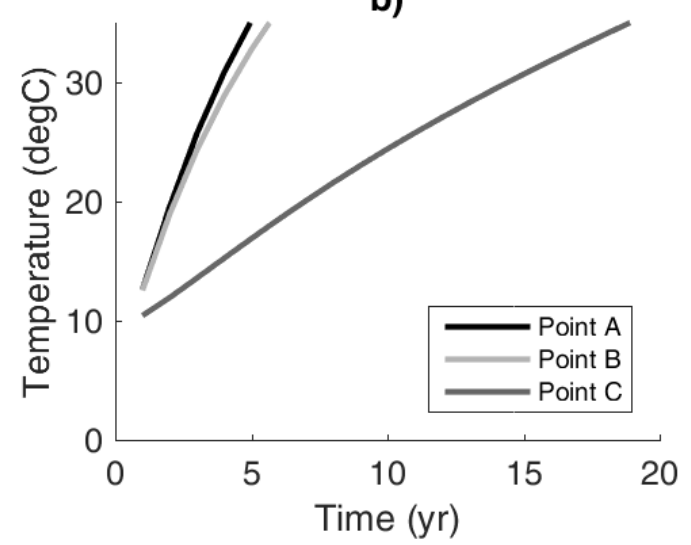

d)

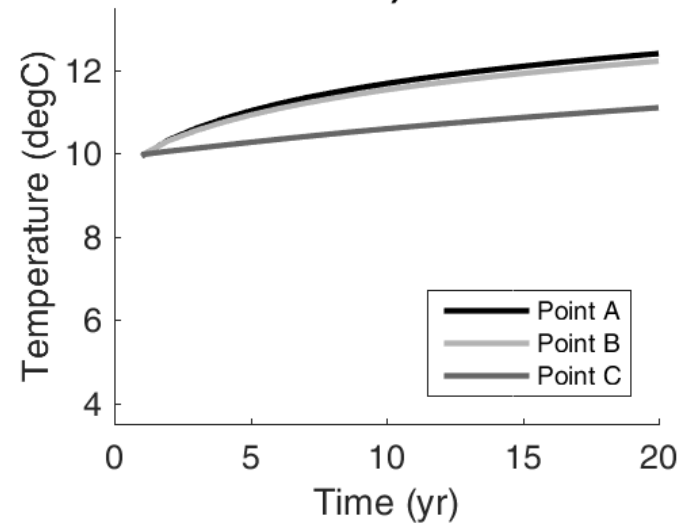

Figure 16: Average ground temperature at points A, B, and C for (a) hospital, (b) fast-food restaurant, (c) residence, and (d) school buildings for $4 \times 4$ borehole configuration

For the $4 \times 4$ borehole configuration, the maximum and minimum ground temperature in the entire soil volume was also studied. The plots are located in Figure 17. In Figure 17a and d, the ground temperature for the hospital and the school change by a small value and the maximum and minimum ground temperatures remain approximately constant. The residence experiences a decrease in overall ground temperature. At the same time, the maximum and minimum ground temperature also decreases. For the fast-food restaurant, the borehole wall temperatures reach a maximum of $50^{\circ} \mathrm{C}$ after a 4.5 year operation period. Due to the large increase in ground temperature, the system is fouled, hence, results beyond 4.5 years (perhaps earlier) are not realistic to model. 
a)

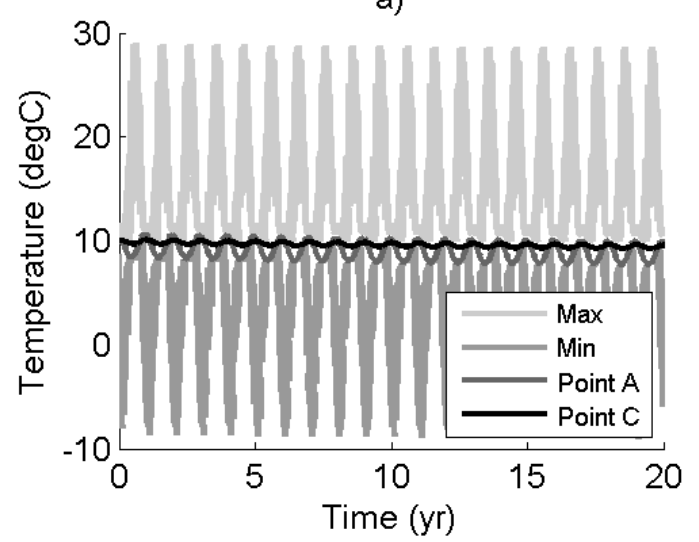

c)

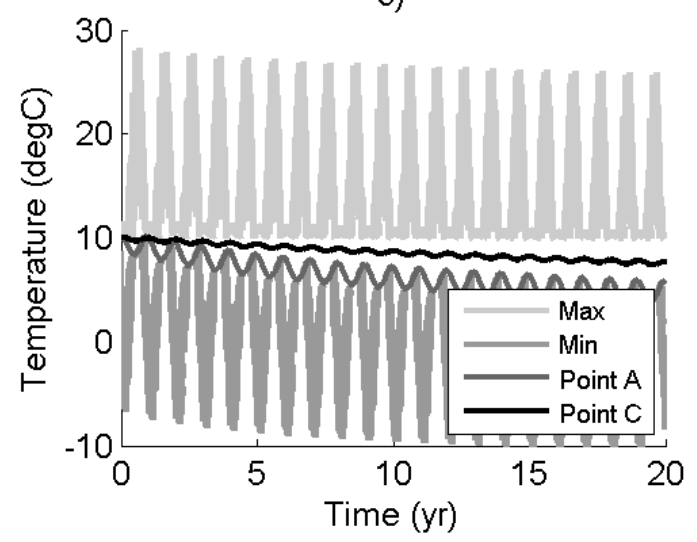

b)

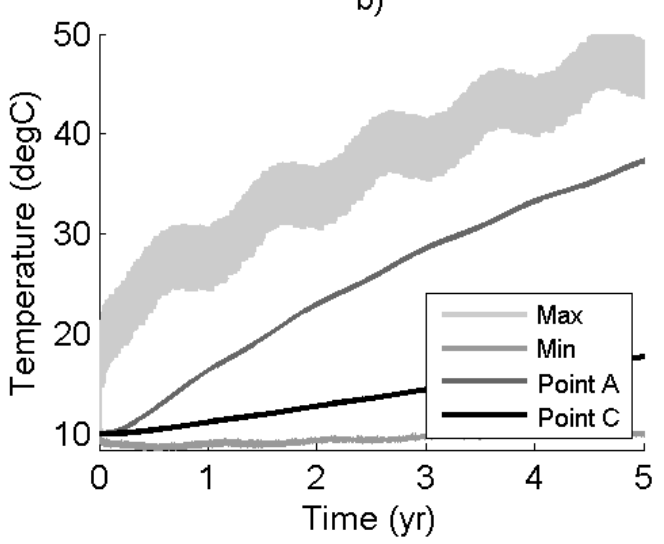

d)

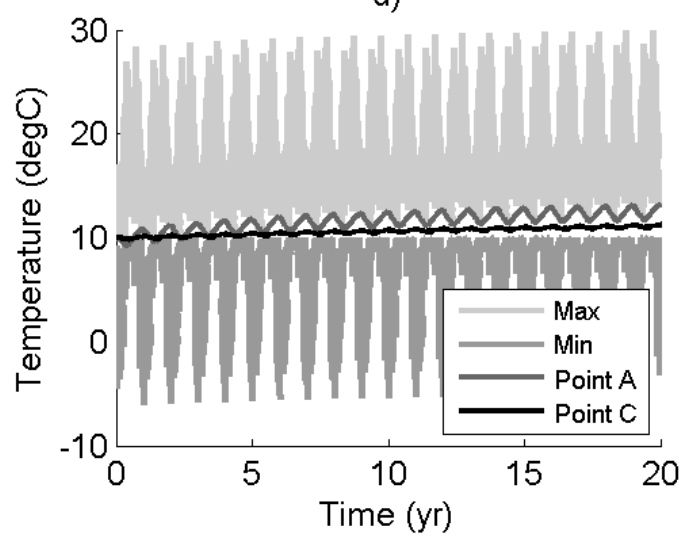

Figure 17: Maximum, minimum, point $\mathrm{A}$, and point $\mathrm{C}$ ground temperature for (a) hospital, (b) fast-food restaurant, (c) residence, and (d) school buildings for 4x4 borehole configuration

\section{$\underline{3.42 \times 8 \text { configuration }}$}

The same analysis for the $4 \times 4$ borehole configuration was repeated for the $2 \times 8$ borehole configuration to compare the effects of borehole layout. The purpose of this analysis is to quantify the potential benefit in ground thermal imbalance in changing the configuration of a borehole field. In this analysis, the boreholes were placed in a 2x8 field as illustrated in Figure 18. Temperatures at points $\mathrm{A}, \mathrm{B}, \mathrm{C}, \mathrm{D}, \mathrm{E}, \mathrm{F}, \mathrm{G}, \mathrm{H}, \mathrm{I}$, and $\mathrm{J}$ were extracted for analysis. Points $\mathrm{D}$ to $\mathrm{J}$ showed similarities to points A and B, respectively, and thus were omitted from the figures. 


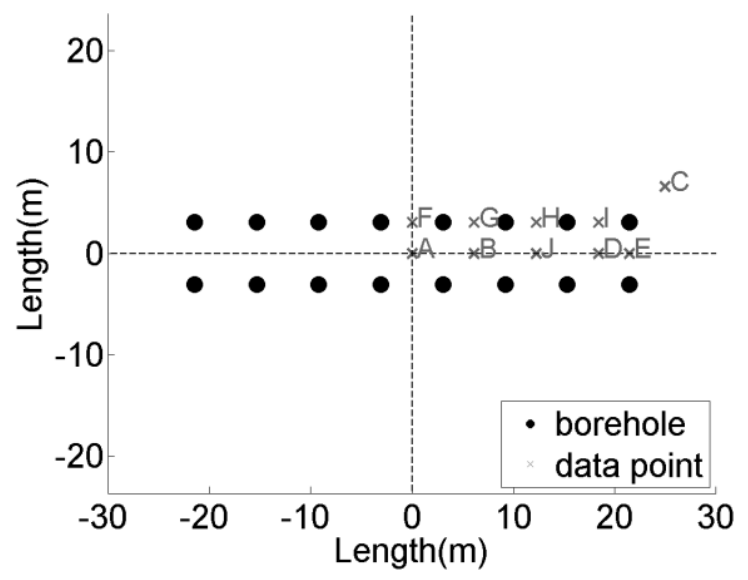

Figure 18: 2x8 borehole layout

The annual averages for ground temperature were calculated and presented in Figure 19. From Figure 19, it can be observed that ground temperature and points A and B are similar. Ground temperature changes quickly in the beginning and slowly at the end of the simulation. At 6.5 years, the ground temperature at point $\mathrm{A}$ for the fast-food restaurant climbed to $35^{\circ} \mathrm{C}$. At 6.5 years, the end of system life is reached since any further increase in ground temperature will not allow heat transfer from the borehole to the surrounding soil. 

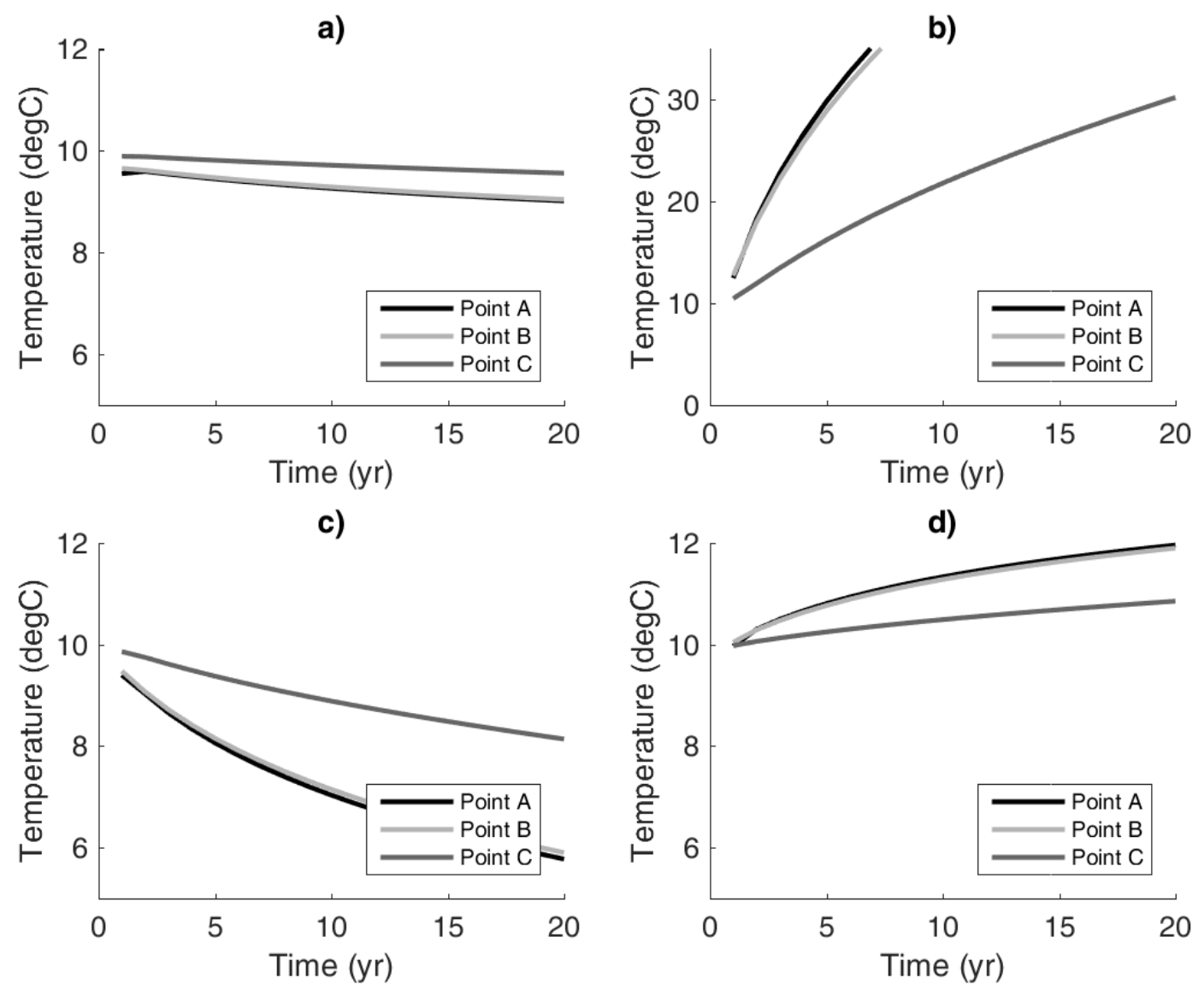

Figure 19: Average ground temperature at points A, B, and C for (a) hospital, (b) fast-food restaurant, (c) residence, and (d) school buildings for $2 \times 8$ borehole configuration

Maximum and minimum ground temperatures show similar trends as Figure 17.

\section{$\underline{3.5 \text { Geometry comparisons }}$}

In this section, the three borehole geometries were compared. For the purposes of comparison, the $2 \times 2$ configuration represents four sets of four boreholes that are far apart, where each set is a $2 \times 2$ configuration. As such, each configuration being compared contains a total of 16 boreholes. The borehole configurations are not necessarily intended to meet the full demands of the 4 buildings presented in the simulations, but rather provide information on temperature variations in a ground 
volume, that would also be representative of an extended domain. The location of maximum heat reduction/accumulation was studied in each case. This location is point $\mathrm{A}$ in all configurations. The temperatures are plotted in Figure 20. The results of the four buildings vary depending on the heating/cooling load imbalance. Using four $2 \times 2$ systems separated at a large distance apart only achieves a $0.5^{\circ} \mathrm{C}$ temperature reduction for the hospital (Figure 20a) after 20 years compared to using a $2 \times 8$ system. The benefits of using a $2 \times 8$ system over a $4 \times 4$ system is also only $0.2^{\circ} \mathrm{C}$.

a)

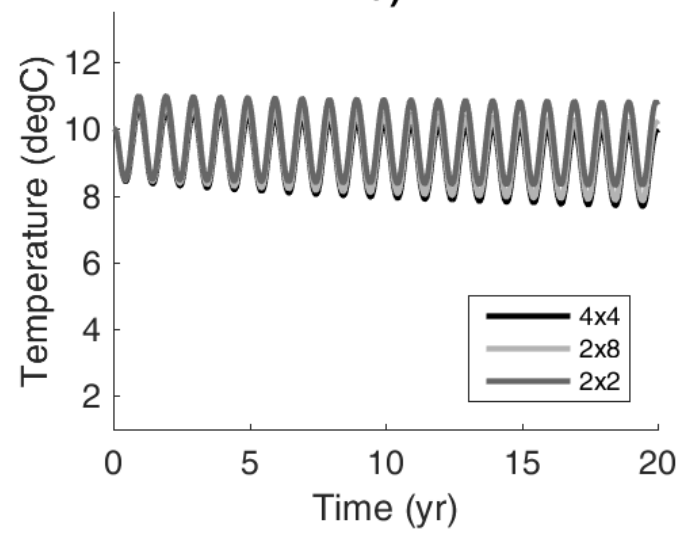

c)

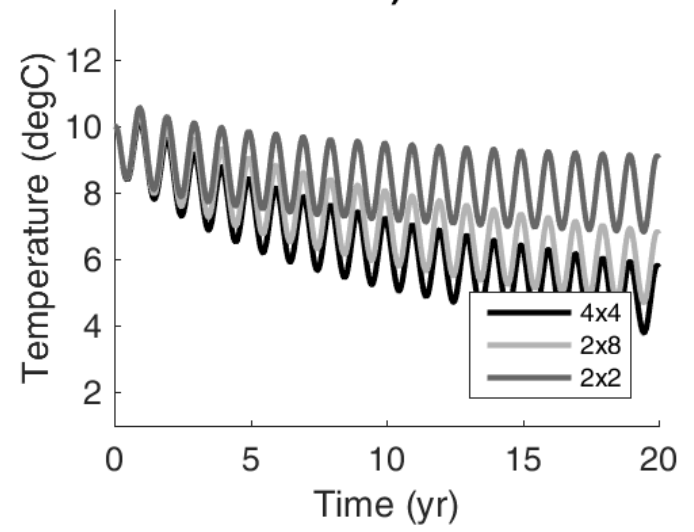

b)

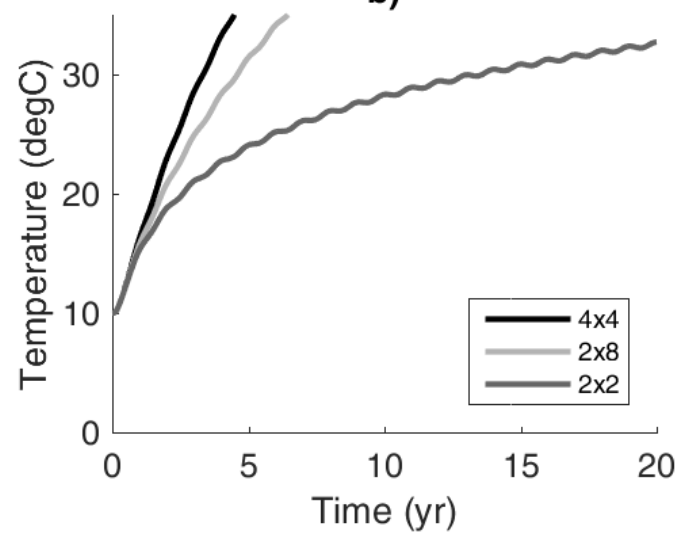

d)

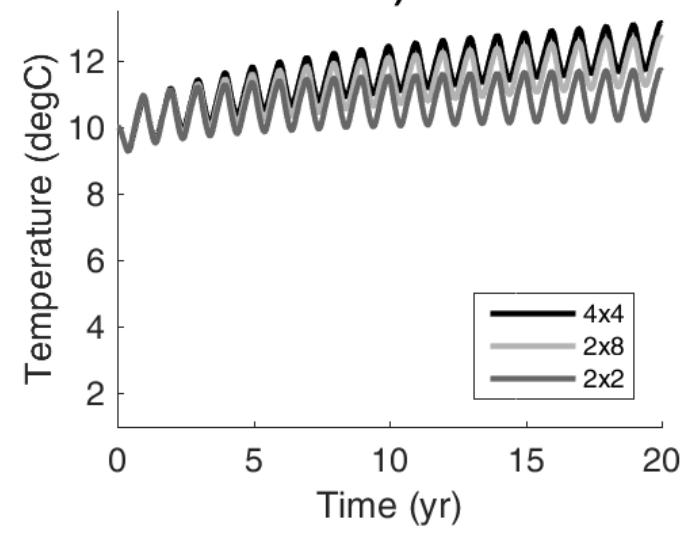

Figure 20: Ground temperature at centre point for (a) hospital, (b) fast-food restaurant, (c) residence, and (d) school buildings for $2 \times 2,4 \times 4$, and $2 \times 8$ configurations. However, different results can be observed in Figure 20c for the residence. When four separate $2 \times 2$ systems are installed with a large distance apart, the average ground temperature after 20 years is $8.8^{\circ} \mathrm{C}\left(1.2^{\circ} \mathrm{C}\right.$ 
drop from initial ground temperature). However, when $2 \times 8$ and $4 \times 4$ systems are used, the ground temperatures after 20 years are $5.8^{\circ} \mathrm{C}\left(4.2^{\circ} \mathrm{C}\right.$ drop $)$ and $4.8^{\circ} \mathrm{C}\left(5.2^{\circ} \mathrm{C}\right.$ drop $)$, respectively. The excess temperature drop can lead to a significant COP reduction in the heating season. By installing a 2x8 system rather than a $4 \times 4$ system, a $1{ }^{\circ} \mathrm{C}$ temperature drop in the ground can be prevented. These results indicate that if space permits, it is more beneficial to install four $2 \times 2$ boreholes systems separated at a large distance apart, rather than one $4 \times 4$ system. In addition, the methodology presented here demonstrates the ability to quantify the benefits of different potential borehole configurations.

In the extremely cooling dominant case of the fast-food restaurant, the ground temperature climbed quickly to $35^{\circ} \mathrm{C}$. As illustrated in Figure $20 \mathrm{~b}$, the only design that lasts through the entire 20 year operating period is the separate $2 \times 2$ installations, albeit with significant ground temperature increase. However, due to space limitations in the property size, this design may not be feasible. In the $2 \times 8$ system, the system life is approximately 6.5 years and the system life is 4.5 years in the $4 \times 4$ system. This result indicates that by simply changing the configuration of the boreholes, the system life can be extended. For this particular building, it would be expected that the system COP will be very low near the end of the system life. A $2 \times 8$ configuration is more favorable in terms of design for thermal imbalance because there is a greater perimeter in the geometry, which provides more space for heat to dissipate to surrounding soil. These results are all under the assumption that borehole lengths are the same, 100m, for each borehole.

Table 7 summarizes the maximum and minimum temperatures at point $\mathrm{A}$ for the four buildings for the three borehole configurations. Year 20 temperatures for the fast-food restaurant were neglected because the ground temperature in inadequate for effective heat transfer. The hospital and school experience the least temperature change in all three borehole configurations. As 
illustrated in Table 6, the heating to cooling hour ratio for the four buildings are 1.322, 0.002 , 1.743, and 1.453 for the hospital, fast-food restaurant, residence, and school, respectively. According to ASHRAE, a 1.6-1.8 cooling to heating ratio should be used to ensure that the system is balanced. However, in the four buildings studied, the least change in ground temperature occurred in the hospital and school (heating hour to cooling hour ratio of 1.322 and 1.453). The residence building with heating to cooling ratio of 1.743 did not result in the minimum change in ground temperature. Discrepancies between these results and the ASHRAE standards may be due to the different system off hours for each building, or to a now improved understanding of the system heat flow. Buildings with large numbers of "system off" hours allow more time for the ground to recover to its initial temperature. This observation iterates the importance to study building loads closely and assess each building separately rather than using rules-of-thumb, whenever possible.

These results also indicate that the greatest ground thermal imbalance occurs in the fast-food restaurant if a system designed for the full load capacity was installed. Potential methods to mitigate the imbalance include hybridizing the GSHP system so that a smaller load demand is required from the GSHP, thereby reducing the ground temperature changes.

Table 7: Summary of maximum, minimum, and temperature and point A for a hospital, fast-food restaurant, residence, and school

\begin{tabular}{ccccccc}
\hline Building & $\begin{array}{c}\text { End of } \\
\text { Year 1 } \\
\text { point A } \\
\left({ }^{\circ} \mathrm{C}\right)\end{array}$ & $\begin{array}{c}\text { End of } \\
\text { Year 20 } \\
\text { point A } \\
\left({ }^{\circ} \mathrm{C}\right)\end{array}$ & $\begin{array}{c}\text { Year 1 } \\
\text { Maximum } \\
\left({ }^{\circ} \mathrm{C}\right)\end{array}$ & $\begin{array}{c}\text { Year 20 } \\
\text { Maximum } \\
\left({ }^{\circ} \mathrm{C}\right)\end{array}$ & $\begin{array}{c}\text { Year 1 } \\
\text { Minimum } \\
\left({ }^{\circ} \mathrm{C}\right)\end{array}$ & $\begin{array}{c}\text { Year 20 } \\
\text { Minimum } \\
\left({ }^{\circ} \mathrm{C}\right)\end{array}$ \\
\hline Hospital & 10.91 & 10.71 & 11.00 & 10.80 & 8.49 & 8.30 \\
$\begin{array}{c}\text { Fast-food } \\
\text { restaurant }\end{array}$ & 15.30 & 32.71 & 15.30 & 32.71 & 10.00 & 32.22
\end{tabular}




\begin{tabular}{|c|c|c|c|c|c|c|}
\hline Residence & 10.46 & 9.03 & 10.56 & 9.11 & 8.45 & 6.82 \\
\hline School & 10.92 & 11.69 & 10.96 & 11.73 & 9.31 & 10.21 \\
\hline \multicolumn{7}{|c|}{$4 \times 4$ configuration } \\
\hline Hospital & 10.59 & 9.87 & 10.65 & 9.93 & 8.43 & 7.68 \\
\hline $\begin{array}{l}\text { Fast-food } \\
\text { restaurant }\end{array}$ & 16.27 & -- & 16.27 & -- & 10.00 & -- \\
\hline Residence & 10.09 & 5.76 & 10.18 & 5.87 & 8.38 & 3.79 \\
\hline School & 10.84 & 13.10 & 10.86 & 13.14 & 9.29 & 11.73 \\
\hline \multicolumn{7}{|c|}{$2 \times 8$ configuration } \\
\hline Hospital & 10.75 & 10.13 & 10.82 & 10.20 & 8.47 & 7.84 \\
\hline $\begin{array}{l}\text { Fast-food } \\
\text { restaurant }\end{array}$ & 15.77 & -- & 15.77 & -- & 10.00 & -- \\
\hline Residence & 10.28 & 6.76 & 10.37 & 6.86 & 8.43 & 4.70 \\
\hline School & 10.87 & 12.67 & 10.91 & 12.71 & 9.30 & 11.25 \\
\hline
\end{tabular}

The study of ground temperature variation is important because of its relationship with GSHP system performance. In a heating dominant scenario, an increase in ground temperature can lead to an inefficient GSHP system because of the resulting low COPs due to inadequate heat transfer temperatures [5].

This model can be used to study the long term temperature variation of GSHP systems. Real building energy demand data can be imported into the model to calculate the borehole boundary conditions. Then, the boundary conditions can be imported in the finite-element model to simulate the long term operation of the GSHP. The industry can use the results of the model to determine whether their design is suitable for their design operating duration. By studying the temperature variations prior to building the system, inefficient GSHPs system designs can be avoided.

\subsection{Conclusions}


In GSHP designs, it is important to closely study the temperature of the soil surrounding the boreholes. Present literature suggests the superimposing of a g-function to model the temperature penalty of various borehole configurations into a single borehole simulation. However, this method cannot model the temperature variation at different locations within the soil domain. The model proposed in the present work provides the temperature distribution surrounding each borehole so that the complete heat extraction/injection effects can be visualized. The model studied the effects of borehole interaction in a 3D manner. In this study, a 20-year analysis was performed for 2x2, $4 \times 4$, and $2 \times 8$ configurations for a hospital, fast-food restaurant, residence, and school. In the $2 \times 2$ configuration, it was observed that the borehole separation distance of $6 \mathrm{~m}$ recommended by ASHRAE was not always sufficient to prevent borehole interaction. As a result, heat accumulation/reduction occurred in the centre of the domain.

In all three configurations, temperature increased quickly in the first few years then the rate of increase slowed. The greatest change in ground temperature occurred in the fast-food restaurant where the building is extremely cooling dominant. The large imbalance of heating and cooling loads in this case caused ground temperature to increase quickly to $35^{\circ} \mathrm{C}$ within the first 4.5 and 6.5 years for $2 \times 8$ and $4 \times 4$ configurations, respectively. From the present study, it can be concluded that the $2 \times 8$ configuration, with its greater perimeter, is more beneficial than the $4 \times 4$ configuration because it has a lower temperature change over 20 years. This small change in ground temperature is because the $2 \times 8$ configuration has a greater perimeter for heat to dissipate to surrounding soil.

This study demonstrated the importance of load balance. Without balanced loads, the ground fouls before reaching the end of the system life, causing system shut down and economic loss. In addition, the importance of accurate energy simulations, modelling, and design should also be noted. To fulfill the knowledge gap that this study presents, further study is needed to examine 
borehole separation distances and the potential of hybridization for more feasible systems for extreme heating/cooling cases. In addition, borehole lengths should also be studied to determine potential benefits of varying borehole lengths in a configuration. Future work in this area also includes study of the use of a thermal storage medium with a GSHP.

\section{Acknowledgements}

The authors would like to thank the Faculty of Engineering and Architectural Science at Ryerson University, Ontario Graduate Scholarship, Natural Sciences and Engineering Research Council of Canada (NSERC), HydroOne, and the Toronto Atmospheric Fund for financial support.

\section{References}

[1] Omer, A., Ground-source heat pumps systems and applications, Renewable and Sustainable Energy Reviews, Vol. 12, No. 2, pp. 344-371, 2008.

[2] Ozyurt, O., Ekinci, D.A. (2011). Experimental study of vertical ground-source heat pump performance evalulation for cold climate in Turkey. Applied Energy, 88, 1257-1265

[3] Florides, G., \& Kalogirou, S., Ground heat exchangers --A review of systems, models and applications, Renewable Energy, Vol. 32, No. 15, pp. 2461-2478, 2007.

[4] Hu, S., Song, W., Zhang, Y., Pan, D. \& Meng, T. (2010). Study of Cold/Hot Stacking Problem Based on Balance Storage of Ground Source Heat Pump. 2010 2nd International Conference on Computer Engineering and Technology, 3, 671-675.

[5] Li, S., Yang, W., \& Zhang, X. (2009). Soil temperature distribution around a U-tube heat exchanger in a multi-function ground source heat pump system. Applied Thermal Engineering, 29(17-18), 3679-3686 
[6] Wu, C., Hui, C., Wang, W., Li, X., Fu, W. (2014) Characteristics of ground temperature and system performance for the intermittent operation of GSHP system. Environment, Energy And Sustainable Development, 123-127.

[7] Rybach, L., \& Eugster, W. (2010). Sustainability aspects of geothermal heat pump operation, with experience from Switzerland. Geothermics, 39(4), 365-369

[8] Zheng, X. (2013). Long-term effects of ground source heat pumps on underground temperature. Proceedings of the 2013 COMSOL Conference

[9] Montagud, C., Coberan, J.M., Ruiz-Calvo, F. (2013). Experimental and modeling analysis of a ground source heat pump system. Applied Energy, 109, 328-336

[10] Man, Y., Yang, H., \& Wang, J. (2010). Study on hybrid ground-coupled heat pump system for air-conditioning in hot-weather areas like Hong Kong. Applied Energy, 87(9), 2826-2833

[11] Alaska Center for Energy and Power \& Cold Climate Housing Research Center. (2011). Ground-Source Heat Pumps in Cold Climates. Retrieved from http://www.cchrc.org/sites/default/files/docs/Ground-Source-Heat-Pumps-in-Cold-Climates.pdf [12] ASHRAE. (2011). 2011 ASHRAE Handbook-HVAC Systems and Equipment SI Edition. Atlanta: ASHRAE.

[13] Bayer, P., de Paly, M., \& Beck, M. (2014). Strategic optimization of borehole heat exchanger field for seasonal geothermal heating and cooling. Applied Energy, 136, 445-453

[14] Lazzari, S., Priarone, A., \& Zanchini, E. (2010). Long-term performance of BHE (borehole heat exchanger) fields with negligible groundwater movement. Energy, 35(12), 4966-4974 
[15] Koohi-Fayegh S., Rosen M.A. (2012). Examination of thermal interaction of multiple vertical ground heat exchangers. Applied Energy, 97, 962-969

[16] Liu, X., and G. Hellström. (2006). Enhancements of an integrated simulation tool for groundsource heat pump system design and energy analysis. Proceedings of Ecostock 2006, NJ: Pomona.

[17] Eskilson, P. (1987). Thermal analysis of heat extraction boreholes. Doctoral thesis, Lund University, Sweden.

[18] Hellström, G., B. Sanner, M. Klugescheid, T. Gonka, and S. Mårtensson. (1997). Experiences with the borehole heat exchanger software EED. Proceedings of Megastock Conference 1997, Japan: Sapporo.

[19] Perez, J.A. (2013) Undrstanding numerically generated g-functions: A study case for a 6x6 borehole field. Master's Thesis. KTH Industrial Engineering and Management.

[20] Fisher, D.E., A. Murugappan, S.K. Padhmanabhan, and S.J. Rees. (2006). Implementation and validation of ground source heat pump system models in an integrated building and system simulation environment. HVAC\&R Research 12(3a):693-710.

[21] Energy+ Inc. "Energy +” 2016. www.energyplus.ca.

[22] Cullin, J R; Montagud, C, PhD; Ruiz-Calvo, F; Spitler, J D, (2006). Experimental Validation of Ground Heat Exchanger Design Methodologies Using Real, Monitored Data. ASHRAE Transactions120: 357-369.

[23] Bernier, M.A., A. Chahla, and P. Pinel. (2008). Long-term ground temperature changes in geo-exchange systems. ASHRAE Transactions 114(2):342-50.

[24] COMSOL Inc., "COMSOL Multiphysics" 2015. www.comsol.com. 
[25] MathWorks Inc., "MATLAB" 2015. www.mathworks.com.

[26] eQUEST. Retrieved November, 2015, from DOE2.com: http://doe2.com/equest/

[27] Kavanaugh, S.P, Rafferty, K.R. Ground-source heat pumps: design of geothermal systems for commercial and institutional buildings. ASHRAE; 1997.

[28] Spitler JD. (2000). GLHEPRO: a design tool for commercial building ground loop heat exchangers. In: Proceedings of the fourth international heat pumps in cold climates conference, Aylmer, Québec. August 17-18, 2000

[29] Lee, C.K. (2011). Effects of multiple ground layers on thermal response test analysis and ground-source heat pump simulation. Applied Energy, 88, 4405-4410

[30] Yang, H., Cui, P., Fang, Z. (2010). Vertical-borehole ground-coupled heat pumps: a review of models and systems. Applied Energy, 87, 16-27

[31] Aydin, M., Sisman, A. (2015). Experimental and computational investigation of multi U-tube boreholes. Applied Energy, 145, 163-171

[32] RETScreen International. (2005). Clean energy project analysis: Ground-source heat pump project analysis. Canada: Ministers of Natural Resource Canada

[33] Kuzmic, N., Law, Y.L.E., \& Dworkin, S.B. (2016). "Numerical heat transfer comparison study of hybrid and non-hybrid ground source heat pump systems," Applied Energy, 165, 919-929.

[34] R. a. Beier, M. D. Smith, and J. D. Spitler (2011). "Reference data sets for vertical borehole ground heat exchanger models and thermal response test analysis," Geothermics, 40(1), 79-85. 
[35] Alavy, M., Nguyen, H.V., Leong, W.H., \& Dworkin, S.B. (2013). A methodology and computerized approach for optimizing hybrid ground source heat pump system design. Renewable Energy, 57, 404-412

[36] Nguyen, H.V., Law, Y.L., Alavy, M., Walsh, P.R., Leong, W.H., \& Dworkin, S.B. (2014). "An analysis of the factors affecting hybrid ground-source heat pump installation potential in North America," Applied Energy, 125, 28-38 